\title{
Effects of the substituents of pyrazole/thiazine ligands on the magnetic properties of chloro-bridged $\mathrm{Cu}(\mathrm{II})$ complexes $^{\mathrm{i}}$
}

\author{
Pablo Torres-García ${ }^{\mathrm{a}}$ Francisco Luna-Giles ${ }^{\mathrm{a}}$, Álvaro Bernalte-García ${ }^{\mathrm{a}}$, Carlos Platas-Iglesias ${ }^{\mathrm{b}}$, \\ David Esteban-Gómez ${ }^{\mathrm{b}}$ and Emilio Viñuelas-Zahínos ${ }^{{ }^{*}}$ \\ a Departamento de Química Orgánica e Inorgánica, Facultad de Ciencias, Universidad de Extremadura, 06071 \\ Badajoz, Spain \\ ${ }^{\text {b }}$ Centro de Investigaciones Científicas Avanzadas (CICA), Departamento de Química Fundamental, Universidade \\ da Coruña, Campus da Zapateira-Rúa da Fraga 10, A Coruña, Spain
}

New Journal of Chemistry, volume 41, issue 17, pages 8818-8827, 07 September 2017

Received 09 May 2017, accepted 11 July 2017, first published 12 July 2017

\section{How to cite:}

Effects of the substituents of pyrazole/thiazine ligands on the magnetic properties of chloro-bridged $\mathrm{Cu}$ (II) complexes. P. Torres-García, F. Luna-Giles, A. Bernalte-García, C. Platas-Iglesias, D. EstebanGómez and E. Viñuelas-Zahínos, New J. Chem., 2017, 41, 8818-8827. DOI: 10.1039/C7NJ01581J.

\begin{abstract}
We have synthesised and characterised the dimeric copper(II) complexes $\left[\{\mathrm{CuCl}(\mathrm{PzTz})\}_{2}(\mu-\mathrm{Cl})_{2}\right]$, $\left[\{\mathrm{CuCl}(\mathrm{DMPzTz})\}_{2}(\mu-\mathrm{Cl})_{2}\right]$ and $\left[\{\mathrm{CuCl}(\mathrm{DPhPzTz})\}_{2}(\mu-\mathrm{Cl})_{2}\right]$ and the monomeric complex $\left[\mathrm{CuCl}_{2}(\mathrm{DMPzTz})\right]$ (PzTz = 2-(1-pyrazolyl)-1,3-thiazine, DMPzTz = 2-(3,5-dimethyl-1-pyrazolyl)-1,3thiazine and DPhPzTz = 2-(3,5-diphenyl-1-pyrazolyl)-1,3-thiazine). Single crystal X-ray diffraction studies show that the geometry around the copper(II) center in the dimeric units is a distorted squared pyramid, while the monomeric compound presents a distorted squared planar coordination. The electronic and magnetic properties of complexes are discussed on the basis of their X-ray structures and EPR spectral studies combined with DFT calculations. Magnetostructural comparisons with structurally similar copper(II) complexes are also carried out. DFT calculations indicate that the dinuclear species are more stable than the mononuclear ones, although the inclusion of methyl or phenyl substituents provokes an important stabilization of the mononuclear forms. DFT calculations fail to predict the sign of the magnetic coupling constants of the complexes whereas multiconfigurational methods, CASSCF/NEVPT2 calculations, predict the correct sign of the exchange coupling constant.
\end{abstract}

Keywords: copper complexes; DFT calculations; crystal structures; electron paramagnetic resonance; magnetic properties

\section{Introduction}

Dimeric $\mathrm{Cu}(\mathrm{II})$ complexes containing simple but efficient $\left\{\mathrm{Cu}_{2}{ }_{2}(\mu-\mathrm{Cl})_{2}\right\}$ moieties have attracted the interest of chemists during the past few decades. Many of these polynuclear complexes were investigated because of their relevance as models for active sites of biomolecules ${ }^{1}$ and also because of their interesting magnetic properties. ${ }^{2,3}$ The study of the magnetic interaction between the central $\mathrm{Cu}(\mathrm{II})$ ions in these complexes has

*emilvin@unex.es 
been the subject of different magneto-structural investigations. ${ }^{2,3}$ However several attempts reported in the literature to achieve a general magneto-structural correlation for these compounds have not yet been successful, likely because it is not easy to establish a simple magneto-structural relationship between the value of the magnetic exchange coupling constant $J$ and structural parameters such as $\mathrm{Cu}-\mathrm{Cl}-\mathrm{Cu}$ bridging angles, $\mathrm{Cu}-\mathrm{Cl}$ bridging bond lengths or $\mathrm{Cu}-\mathrm{Cu}$ distances. ${ }^{3 \mathrm{f}}$ The reasons for these difficulties are probably related to the large number of existing compounds with a huge variation in structural features (i.e. bond distances and angles involving the $\mathrm{Cu}$ (II) ions), which allows a variety of pathways for the magnetic interactions to occur. ${ }^{2 \mathrm{~b}, \mathrm{c}, \mathrm{l}, \mathrm{q}-\mathrm{v}, 4}$ Nevertheless, the rational design of new magnetic materials will be facilitated by a deeper understanding of magneto-structural correlations.

The structures of dimeric $\mathrm{Cu}$ (II) complexes may change by introducing subtle changes in the ligand structure or crystal packing forces. These small structural changes can have important effects on the magnetic properties of the system. ${ }^{2 \mathrm{~m}}$ As a result, complexes with very similar structural features change from antiferromagnetic to ferromagnetic behaviour. ${ }^{3 \mathrm{c}}$

Here, we present the synthesis, structural characterisation and variable temperature magnetic properties of the dimeric $\mathrm{Cu}(\mathrm{II})$ complexes $\left[\{\mathrm{CuCl}(\mathrm{PzTz})\}_{2}(\mu-\mathrm{Cl})_{2}\right] \quad(\mathrm{PzTz}=2$-(1-pyrazolyl)-1,3-thiazine), $\left[\{\mathrm{CuCl}(\mathrm{DMPzTz})\}_{2}(\mu-\mathrm{Cl})_{2}\right] \quad(\mathrm{DMPzTz} \quad=\quad$ 2-(3,5-dimethyl-1-pyrazolyl)-1,3-thiazine) and $\left[\{\mathrm{CuCl}(\mathrm{DPhPzTz})\}_{2}(\mu-\mathrm{Cl})_{2}\right](\mathrm{DPhPzTz}=2$-(3,5-diphenyl-1-pyrazolyl)-1,3-thiazine). The aim of studying this series of ligands is to assess the effect that the bulkiness of the substituents at positions 3 and 5 of the pyrazole ring may have on the structure and magnetic properties of the corresponding $\mathrm{Cu}$ (II) complexes (see Scheme 1). Likewise, the crystal structure of the monomeric $\mathrm{Cu}$ (II) complex $\left[\mathrm{CuCl}_{2}(\mathrm{DMPzTz})\right]$ is reported. The magnetic properties of the complexes were explored and discussed on the basis of electron paramagnetic resonance (EPR) spectroscopy and magnetic susceptibility measurements combined with DFT studies and multiconfigurational calculations based on the complete active space self-consistent field (CASSCF) method.
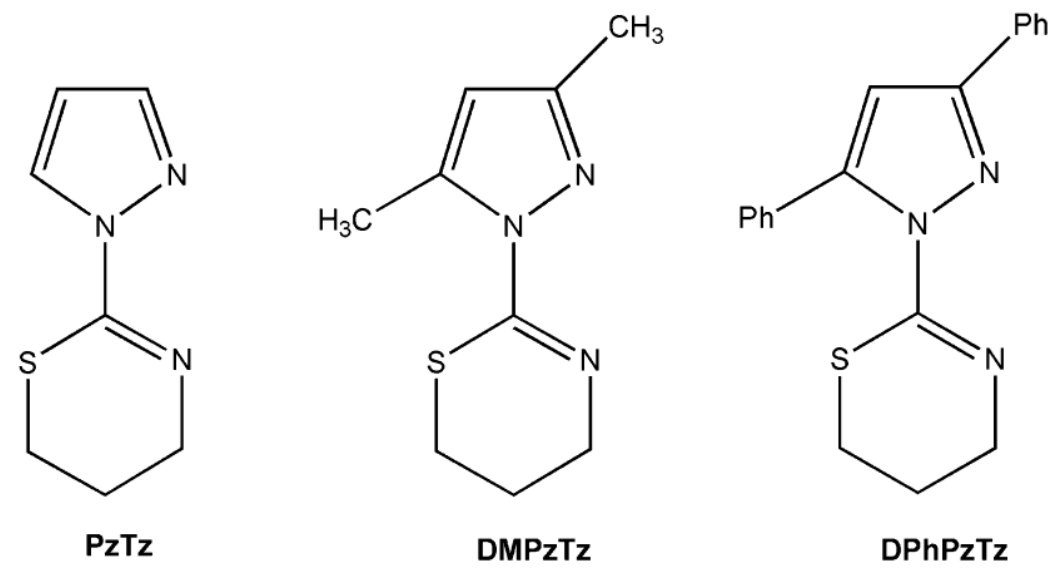

Scheme 1. Organic pyrazole/thiazine ligands studied in this work.

\section{Results and discussion}

Synthesis and general aspects of complexes

The dimeric copper(II) complexes $\quad\left[\{\mathrm{CuCl}(\mathrm{PzTz})\}_{2}(\mu-\mathrm{Cl})_{2}\right], \quad\left[\{\mathrm{CuCl}(\mathrm{DMPzTz})\}_{2}(\mu-\mathrm{Cl})_{2}\right]$ and $\left[\{\mathrm{CuCl}(\mathrm{DPhPzTz})\}_{2}(\mu-\mathrm{Cl})_{2}\right]$ were obtained by reaction of the organic ligand (PzTz, DMPzTz or DPhPzTz) 
and $\mathrm{CuCl}_{2} \cdot 2 \mathrm{H}_{2} \mathrm{O}$ in methanol solution. In the case of $\left[\{\mathrm{CuCl}(\mathrm{DMPzTz})\}_{2}(\mu-\mathrm{Cl})_{2}\right]$ slow evaporation of the reaction mixture resulted in the formation of light green crystals mixed with a dark green solid. The mother liquor was decanted, and the light green crystals were segregated from the dark green solid by hand picking under a stereomicroscope. When the reaction was repeated using acetonitrile as a solvent only dark green crystals were obtained by evaporation of the solvent, which corresponded to the monomeric copper(II) complex $\left[\mathrm{CuCl}_{2}(\mathrm{DMPzTz})\right]$. To check whether the monomeric complex could be isolated with the other two ligands (PzTz and DPhPzTz), the complexation reactions were carried out again in acetonitrile. However these reactions turned out to yield only the dimeric complexes.

The electronic spectra of the binuclear complexes are in accordance with five coordinated $\mathrm{Cu}(\mathrm{II})$ ions having distorted square pyramidal geometries. The spectra show a broad band expanding in the interval of 12920 $13990 \mathrm{~cm}^{-1}$ due to all four $\mathrm{d}-\mathrm{d}$ transitions $\left({ }^{2} \mathrm{~A}\left[\left(\mathrm{~d}_{z}{ }^{2}\right)^{1}\right],{ }^{2} \mathrm{~A}\left[\left(\mathrm{~d}_{x y}\right)^{1}\right],{ }^{2} \mathrm{~A}\left[\left(\mathrm{~d}_{x z}\right)^{1}\right],{ }^{2} \mathrm{~A}\left[\left(\mathrm{~d}_{y z}\right)^{1}\right] \leftarrow{ }^{2} \mathrm{~A}\left[\left(\mathrm{~d}_{x}{ }^{2}-y^{2}\right)^{1}\right]\right) .{ }^{5}$ The spectra also display strong absorptions at $26950-32680 \mathrm{~cm}^{-1}$ that can be assigned as ligand $\rightarrow \mathrm{Cu}(\mathrm{II})$ charge transfer bands. ${ }^{20,6}$

Vibrational spectra of the copper(II) complexes (Fig. S1-S8, ESI ${ }^{\mathrm{i}}$ ) show a strong absorption band in the range of $1592-1614 \mathrm{~cm}^{-1}$ corresponding to the $\Psi_{1}[v(\mathrm{C}=\mathrm{N})]$ vibration of the thiazine ring. These bands are shifted negatively relative to the uncoordinated thiazine ring of the respective ligands $\left(1635-1639 \mathrm{~cm}^{-1}\right)$ because of a retrocoordination effect, which signals coordination via the thiazine nitrogen atom. ${ }^{7}$ However, the bands attributable to pyrazole ring vibrations experience a shift in the opposite direction, which nevertheless confirms coordination through the pyrazole nitrogen atom. On the other hand, the 500-150 $\mathrm{cm}^{-1}$ region of the spectra presents several bands corresponding to the $v(\mathrm{Cu}-\mathrm{Cl}), v\left(\mathrm{Cu}-\mathrm{N}_{\text {pyrazole }}\right)$ and $v(\mathrm{Cu}-$ $\mathrm{N}_{\text {thiazine }}$ ) metal-ligand stretching vibrations.

\section{Crystal structural analysis}

The pertinent crystallographic data for the structures of the copper(II) complexes are given in Table S1 $\left(\right.$ ESI $\left.^{\mathrm{i}}\right)$. ORTEP drawings of the molecular structures of the complexes are depicted in Fig. 1, and the selected bond lengths and angles are given in Table 1 .

The structures of dimeric complexes are similar and consist of centrosymmetric dimeric $\left[\{\mathrm{CuCl}(\mathrm{L})\}_{2}(\mu-\mathrm{Cl})_{2}\right]$ (L = PzTz, DMPzTz or DPhPzTz) units. The two $\mathrm{Cu}(\mathrm{II})$ centres are joined by two chloride bridging ligands forming a four-membered ring. A terminal chloride ligand and a bidentate chelating 1-pyrazolyl-1,3-thiazine ligand complete five-coordination at each metal. The bridging chloride anions are bonded to the two copper atoms in an asymmetric fashion with significantly different bond distances: 2.292(1) and 2.795(1) $\AA$ in complex $\left[\{\mathrm{CuCl}(\mathrm{PzTz})\}_{2}(\mu-\mathrm{Cl})_{2}\right], 2.273(1)$ and 2.580(1) $\AA$ in complex $\left[\{\mathrm{CuCl}(\mathrm{DMPzTz})\}_{2}(\mu-\mathrm{Cl})_{2}\right]$, and 2.282(1) and 2.675(2) $\AA$ in complex $\left[\{\mathrm{CuCl}(\mathrm{DPhPzTz})\}_{2}(\mu-\mathrm{Cl})_{2}\right]$. The bridging $\mathrm{Cu}_{2} \mathrm{Cl}_{2}$ units have a strictly planar geometry imposed by the presence of a crystallographic inversion centre.

The coordination polyhedron around the copper centres can be described as a distorted square pyramid, in accordance with the values ${ }^{8,9}$ obtained for $\tau_{5}$ and $\Delta$ (Table 2). The degree of distortion of the square pyramids depends on the substituents at positions 3 and 5 of the pyrazole rings. Thus, in $\left[\{\mathrm{CuCl}(\mathrm{PzTz})\}_{2}(\mu-\mathrm{Cl})_{2}\right]$ the distortion is lower than in the analogues containing phenyl and methyl substituents. The basal plane of the square pyramid is delineated by one thiazine nitrogen atom $\mathrm{N}(1)$, one pyrazole nitrogen atom $\mathrm{N}(3)$, the bridging chloride ligand $\mathrm{Cl}(1)$ and the terminal chloride ligand $\mathrm{Cl}(2)$, while the apical position is occupied by the other bridging chloride ligand $\mathrm{Cl}(1 \mathrm{a})$. As a result, the dimeric complexes present two square pyramids sharing one base-to-apex edge, with parallel basal planes. The $\mathrm{Cu}$ atom is situated over the mean plane formed by the four basal donor atoms displaced towards the apical atom $\mathrm{Cl}(1 \mathrm{a})$, with a greater distance from the metallic atom to the mean least-squares basal plane when the distortion of the square pyramid is higher $\left(0.122 \AA\right.$ in $\left[\{\mathrm{CuCl}(\mathrm{PzTz})\}_{2}(\mu-\mathrm{Cl})_{2}\right] ; \quad 0.234 \AA$ in $\left[\{\mathrm{CuCl}(\mathrm{DMPzTz})\}_{2}(\mu-\mathrm{Cl})_{2}\right] ; \quad 0.273 \AA$ in $\left.\left[\{\mathrm{CuCl}(\mathrm{DPhPzTz})\}_{2}(\mu-\mathrm{Cl})_{2}\right]\right)$. The four bond distances involving donor atoms of the basal plane are 
considerably shorter than the $\mathrm{Cu}-\mathrm{Cl}(1 \mathrm{a})$ distances. This is in line with the structures of different $\mathrm{Cu}$ (II) complexes having a square pyramidal coordination geometry, in which the distances involving basal donor atoms are shorter than the distances involving apical coordination. ${ }^{10}$

a)

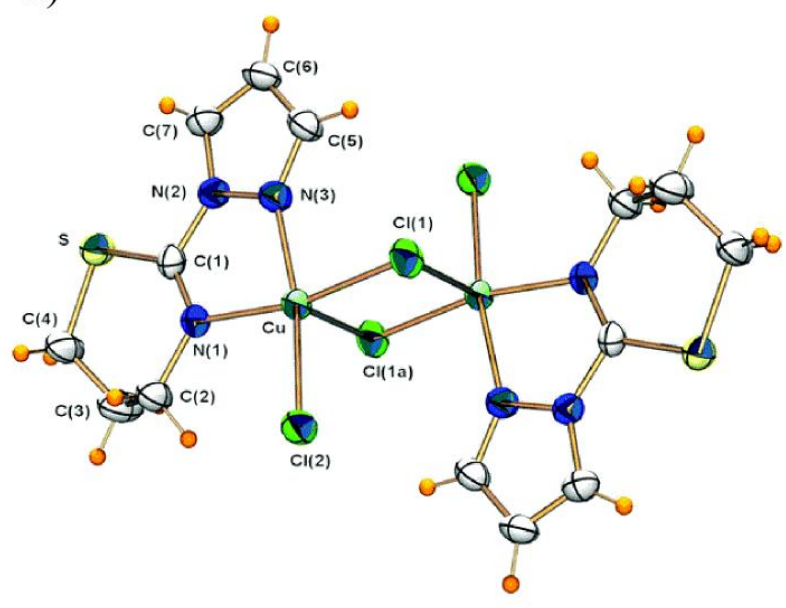

c)

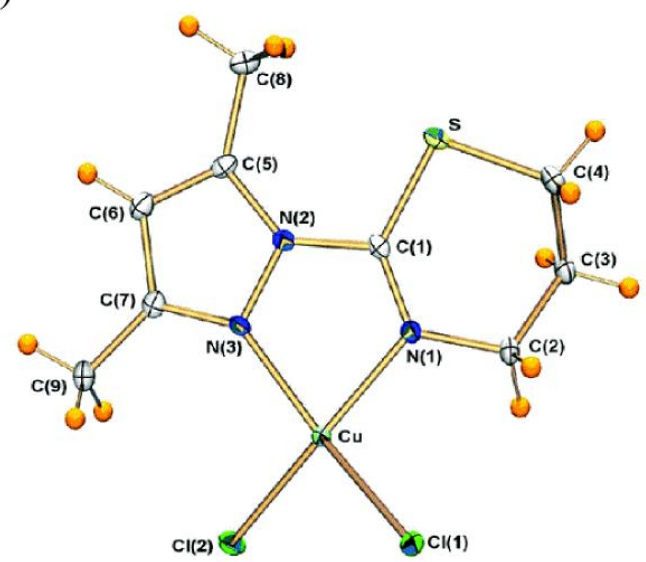

b)

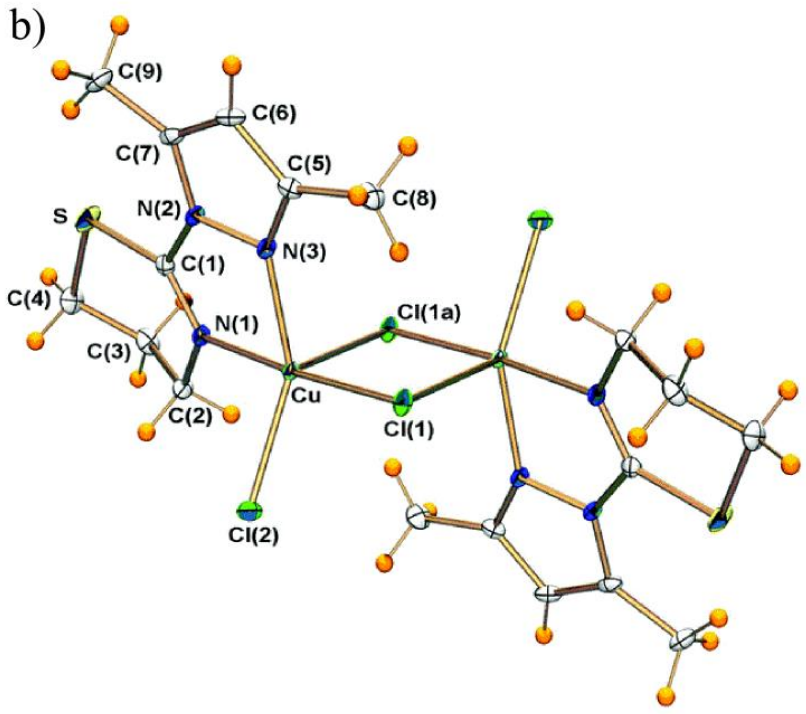

d)

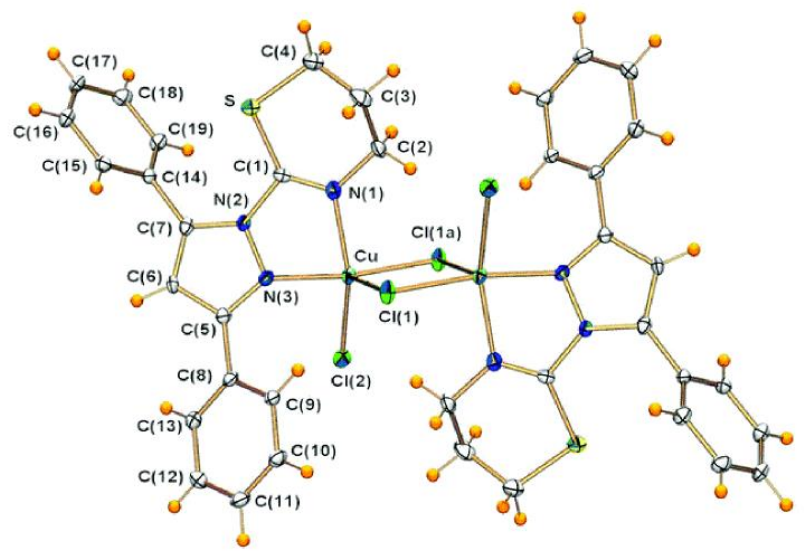

Fig. 1. Molecular structures of (a) $\left[\{\mathrm{CuCl}(\mathrm{PzTz})\}_{2}(\mu-\mathrm{Cl})_{2}\right]$, (b) $\left[\{\mathrm{CuCl}(\mathrm{DMPzTz})\}_{2}(\mu-\mathrm{Cl})_{2}\right]$, (c) $\left[\mathrm{CuCl}_{2}(\mathrm{DMPzTz})\right]$ and $(\mathrm{d})\left[\{\mathrm{CuCl}(\mathrm{DPhPzTz})\}_{2}(\mu-\mathrm{Cl})_{2}\right]$.

The structure of $\left[\mathrm{CuCl}_{2}(\mathrm{DMPzTz})\right]$ consists of discrete neutral monomeric units in which the environment around the copper(II) atom may be described as distorted square planar, as demonstrated by the calculated $\tau_{4}$ value. ${ }^{11}$ The metallic atom is directly bound to two chloride ligands and one DMPzTz ligand, which coordinates through the pyrazole and thiazine nitrogen atoms forming a five-membered chelate ring.

The $\mathrm{Cu}$ (II)-ligand bond lengths and intramolecular $\mathrm{Cu}(\mathrm{II}) \cdots \mathrm{Cu}$ (II) distances in the complexes reported here have been compared with the average value calculated from the structures of similar compounds found in the Cambridge Structural Database (CSD, version 5.37, May 2016) ${ }^{12}$ (see Table S2, ESI ${ }^{i}$ ). Generally, the experimental bond lengths are comparable to the calculated average values for similar compounds, with the exception of the $\mathrm{Cu}-\mathrm{Cl}(1 \mathrm{a})$ distance in $\left[\{\mathrm{CuCl}(\mathrm{DMPzTz})\}_{2}(\mu-\mathrm{Cl})_{2}\right]$, which is shorter than the mean values found in other dimeric complexes. 
Table 1. Selected bond lengths $(\AA)$ and angles $\left({ }^{\circ}\right)$ for copper complexes. ${ }^{a}$

\begin{tabular}{lllll}
\hline & {$\left[\{\mathrm{CuCl}(\mathrm{PzTz})\}_{2}(\mu-\mathrm{Cl})_{2}\right]$} & {$\left[\{\mathrm{CuCl}(\mathrm{DMPzTz})\}_{2}(\mu-\mathrm{Cl})_{2}\right]$} & {$\left[\mathrm{CuCl}_{2}(\mathrm{DMPzTz})\right]$} & {$\left[\{\mathrm{CuCl}(\mathrm{DPhPzTz})\}_{2}(\mu-\mathrm{Cl})_{2}\right]$} \\
\hline $\mathrm{Cu}-\mathrm{N}(1)$ & $2.050(3)$ & $1.998(2)$ & $1.985(1)$ & $2.022(3)$ \\
$\mathrm{Cu}-\mathrm{N}(3)$ & $1.988(3)$ & $2.029(2)$ & $1.993(2)$ & $2.026(3)$ \\
$\mathrm{Cu}-\mathrm{Cl}(1)$ & $2.292(1)$ & $2.273(1)$ & $2.237(1)$ & $2.282(1)$ \\
$\mathrm{Cu}-\mathrm{Cl}(1 \mathrm{a})^{a}$ & $2.795(1)$ & $2.580(1)$ & & $2.675(2)$ \\
$\mathrm{Cu}-\mathrm{Cl}(2)$ & $2.227(1)$ & $2.264(1)$ & $2.203(1)$ & $2.244(1)$ \\
$\mathrm{N}(1)-\mathrm{Cu}-\mathrm{N}(3)$ & $78.6(1)$ & $78.8(1)$ & $80.0(1)$ & $78.4(1)$ \\
$\mathrm{N}(1)-\mathrm{Cu}-\mathrm{Cl}(1)$ & $168.5(1)$ & $175.4(1)$ & $93.7(1)$ & $94.1(1)$ \\
$\mathrm{N}(1)-\mathrm{Cu}-\mathrm{Cl}(1 \mathrm{a})$ & $91.2(1)$ & $87.7(1)$ & & $89.0(1)$ \\
$\mathrm{N}(1)-\mathrm{Cu}-\mathrm{Cl}(2)$ & $95.0(1)$ & $92.0(1)$ & $161.6(1)$ & $157.2(1)$ \\
$\mathrm{N}(3)-\mathrm{Cu}-\mathrm{Cl}(1)$ & $90.4(1)$ & $98.2(1)$ & & $172.2(1)$ \\
$\mathrm{N}(3)-\mathrm{Cu}-\mathrm{Cl}(1 \mathrm{a})$ & $90.0(1)$ & $97.2(1)$ & $98.2(1)$ & $95.3(1)$ \\
$\mathrm{N}(3)-\mathrm{Cu}-\mathrm{Cl}(2)$ & $169.4(1)$ & $146.3(1)$ & & $91.5(1)$ \\
$\mathrm{Cl}(1)-\mathrm{Cu}-\mathrm{Cl}(1 \mathrm{a})$ & $98.6(1)$ & $89.3(1)$ & $95.0(1)$ & $94.6(1)$ \\
$\mathrm{Cl}(1)-\mathrm{Cu}-\mathrm{Cl}(2)$ & $95.3(1)$ & $92.4(1)$ & & $112.5(1)$ \\
$\mathrm{Cl}(1 \mathrm{a})-\mathrm{Cu}-\mathrm{Cl}(2)$ & $92.5(1)$ & $114.9(1)$ & & \\
\hline
\end{tabular}

${ }^{a}$ Symmetry code: $0.5-x, 0.5-y,-z$ for $\left[\{\mathrm{CuCl}(\mathrm{PzTz})\}_{2}(\mu-\mathrm{Cl})_{2}\right]$ and $\left[\{\mathrm{CuCl}(\mathrm{DMPzTz})\}_{2}(\mu-\mathrm{Cl})_{2}\right] ; 1-x, 1-y,-z$ for $\left[\{\mathrm{CuCl}(\mathrm{DPhPzTz})\}_{2}(\mu-\mathrm{Cl})_{2}\right]$.

Table 2. Quantification of the coordination geometry of the polyhedra in the copper(II) complexes.

\begin{tabular}{lllll}
\hline $\begin{array}{l}\text { Geometrical } \\
\text { parameters }\end{array}$ & {$\left[\{\mathrm{CuCl}(\mathrm{PzTz})\}_{2}(\mu-\mathrm{Cl})_{2}\right]$} & {$\left[\{\mathrm{CuCl}(\mathrm{DMPzTz})\}_{2}(\mu-\mathrm{Cl})_{2}\right]$} & {$\left[\mathrm{CuCl}_{2}(\mathrm{DMPzTz})\right]$} & {$\left[\{\mathrm{CuCl}(\mathrm{DPhPzTz})\}_{2}(\mu-\mathrm{Cl})_{2}\right]$} \\
\hline$\tau_{5}{ }^{a}$ & 0.02 & 0.48 & 0.22 \\
$\Delta^{b}$ & 0.86 & 0.74 & 0.89 \\
$\tau^{c}{ }^{c}$ & & & 0.30 & \\
\hline
\end{tabular}

${ }^{a} \tau_{5}=1$ for a trigonal bipyramidal geometry and 0 for a perfect square pyramidal geometry. ${ }^{b} \Delta=1$ for a square pyramidal geometry and 0 for a perfect trigonal bipyramidal geometry. ${ }^{c} \tau_{4}=1$ for a perfect tetrahedral geometry and 0 for a perfect square planar geometry.

A comparison of the crystal structures of the $\left[\{\mathrm{CuCl}(\mathrm{PzTz})\}_{2}(\mu-\mathrm{Cl})_{2}\right]$ and $\left[\{\mathrm{CuCl}(\mathrm{DPhPzTz})\}_{2}(\mu-\mathrm{Cl})_{2}\right]$ complexes with those of the free ligands $\mathrm{PzTz}$ and $\mathrm{DPhPzTz}^{13}$ evidences a drastic change in the conformation of the ligand to allow coordination through both $\mathrm{N}(1)$ and $\mathrm{N}(3)$. Indeed, the $\mathrm{N}(1)-\mathrm{C}(1)-\mathrm{N}(2)-$ $\mathrm{N}$ (3) torsional angles take values of 165.3 and $123.6^{\circ}$ for PzTz and DPhPzTz, respectively, ${ }^{13}$ while the values observed in the corresponding complexes are 7.1 and $18.4^{\circ}$. 
The increasing steric hindrance introduced by the replacement of hydrogen atoms in positions 3 or 5 of the pyrazole ring by methyl and phenyl groups produces a drastic structural change in $\left[\{\mathrm{CuCl}(\mathrm{DPhPzTz})\}_{2}(\mu-\right.$ $\mathrm{Cl})_{2}$ ], which presents a different arrangement of the organic ligand that minimizes steric effects. Indeed, the coordination environment in $\left[\{\mathrm{CuCl}(\mathrm{DMPzTz})\}_{2}(\mu-\mathrm{Cl})_{2}\right]$ and $\left[\{\mathrm{CuCl}(\mathrm{PzTz})\}_{2}(\mu-\mathrm{Cl})_{2}\right]$ complexes is such that the nitrogen atom of the thiazine ring $\mathrm{N}(1)$ occupies a cis position in the basal plane of the square pyramid with respect to the terminal chloride ligand $\mathrm{Cl}(2)$ ( cis- $\mathrm{N}(1), \mathrm{Cl}(2)$ isomer). However, $\mathrm{N}(1)$ and $\mathrm{Cl}(2)$ are clearly occupying trans positions in the $\left[\{\mathrm{CuCl}(\mathrm{DPhPzTz})\}_{2}(\mu-\mathrm{Cl})_{2}\right]$ complex (trans- $\left.\mathrm{N}(1), \mathrm{Cl}(2)\right)$. Finally, the steric strain generated by the presence of methyl groups at positions 3 and 5 of the pyrazole ring provokes a significant lengthening of the $\mathrm{Cu}-\mathrm{N}(3)$ distance, with a concomitant shortening of the $\mathrm{Cu}-\mathrm{N}(1)$ bond. Most likely the isolation of the mononuclear complex $\left[\mathrm{CuCl}_{2}(\mathrm{DMPzTz})\right]$ is also related to steric effects brought about by the presence of the methyl groups (see the DFT section below).

$\underline{\text { EPR and magnetic study }}$

The EPR parameters obtained for the copper(II) complexes are presented in Table 3.

Table 3. EPR parameters of copper(II) complexes.

\begin{tabular}{|c|c|c|c|c|c|c|c|}
\hline \multirow[b]{2}{*}{ Compound } & \multicolumn{3}{|c|}{ Solid (298 K) } & \multicolumn{4}{|c|}{$\mathrm{MeOH}(77 \mathrm{~K})$} \\
\hline & $g_{\text {iso }}$ & $g_{\|}$ & $g_{\perp}$ & $g_{\|}$ & $g_{\perp}$ & $A_{\|}^{a}$ & $G$ \\
\hline$\left[\{\mathrm{CuCl}(\mathrm{PzTz})\}_{2}(\mu-\mathrm{Cl})_{2}\right]$ & - & 2.248 & 2.057 & 2.248 & 2.066 & 153 & 3.76 \\
\hline$\left[\{\mathrm{CuCl}(\mathrm{DMPzTz})\}_{2}(\mu-\mathrm{Cl})_{2}\right]$ & - & 2.258 & 2.058 & 2.300 & 2.070 & 160 & 4.55 \\
\hline$\left[\mathrm{CuCl}_{2}(\mathrm{DMPzTz})\right]$ & - & 2.198 & 2.070 & 2.300 & 2.070 & 160 & 4.55 \\
\hline$\left[\{\mathrm{CuCl}(\mathrm{DPhPzTz})\}_{2}(\mu-\mathrm{Cl})_{2}\right]$ & 2.089 & - & - & 2.380 & 2.086 & 170 & 4.42 \\
\hline
\end{tabular}

${ }^{a}$ Units: $\times 10^{-1} \mathrm{~cm}^{-1}$.

The spectra in the solid state of $\left[\{\mathrm{CuCl}(\mathrm{PzTz})\}_{2}(\mu-\mathrm{Cl})_{2}\right],\left[\{\mathrm{CuCl}(\mathrm{DMPzTz})\}_{2}(\mu-\mathrm{Cl})_{2}\right]$ and $\left[\mathrm{CuCl}_{2}(\mathrm{DMPzTz})\right]$ (Fig. S9-S12, ESI $)$ are typical of axial species. The values of the geometric parameter $G\left[G=\left(g_{\|}-2\right) /\left(g_{\perp}-\right.\right.$ 2)] were found to be in the range of 3.0-6.0 with $g_{\|}>g_{\perp}>2.0023$, thus indicating that the unpaired electron is located in a $\mathrm{d}_{x}{ }^{2}-y^{2}$ orbital associated with a square-pyramidal stereochemistry, in good agreement with the crystallographic data. ${ }^{14}$ The spectrum of $\left[\{\mathrm{CuCl}(\mathrm{DPhPzTz})\}_{2}(\mu-\mathrm{Cl})_{2}\right]$ shows an isotropic form $\left(g_{\text {iso }}=2.089\right)$ that does not give information on the electronic ground state of the copper(II) ion present in the compound. ${ }^{15}$

The EPR spectra of complexes recorded in frozen $\mathrm{MeOH}$ at $77 \mathrm{~K}$ (Fig. S13-S16, ESI ${ }^{\mathrm{i}}$ ) also correspond to axial species, showing hyperfine lines. The spectra of $\left[\{\mathrm{CuCl}(\mathrm{DMPzTz})\}_{2}(\mu-\mathrm{Cl})_{2}\right]$ and $\left[\mathrm{CuCl}_{2}(\mathrm{DMPzTz})\right]$ recorded in frozen $\mathrm{MeOH}$ are virtually identical, and provide parameters very similar to those obtained in the solid state for $\left[\{\mathrm{CuCl}(\mathrm{DMPzTz})\}_{2}(\mu-\mathrm{Cl})_{2}\right]$. This indicates that $\left[\{\mathrm{CuCl}(\mathrm{DMPzTz})\}_{2}(\mu-\mathrm{Cl})_{2}\right]$ is the predominant species in $\mathrm{MeOH}$ solution, at least at low temperature. Moreover, the $g$ values obtained for $\left[\{\mathrm{CuCl}(\mathrm{PzTz})\}_{2}(\mu-\mathrm{Cl})_{2}\right]$ and $\left[\{\mathrm{CuCl}(\mathrm{DMPzTz})\}_{2}(\mu-\mathrm{Cl})_{2}\right]$ in the solid state at room temperature and in frozen solution are similar, suggesting that the geometry is the same at both temperatures.

The observed molar magnetic susceptibility at room temperature for $\left[\mathrm{CuCl}_{2}(\mathrm{DMPzTz})\right]$ provides a fully corrected magnetic moment of 1.85 BM. This value is in the range of 1.75-2.20 BM typical for mononuclear copper(II) complexes without $\mathrm{Cu}-\mathrm{Cu}$ interactions, regardless of the stereochemistry, in good agreement with crystallographic data. ${ }^{16}$ 
Variable temperature (2.0-300 K) magnetic susceptibility data were collected for polycrystalline samples of the $\left[\{\mathrm{CuClL}\}_{2}(\mu-\mathrm{Cl})_{2}\right](\mathrm{L}=\mathrm{PzTz}, \mathrm{DMPzTz}$ or DPhPzTz $)$ complexes. The high-temperature data $(T>140 \mathrm{~K})$ were fit to a Curie-Weiss relationship, yielding $C=0.93 \mathrm{~cm}^{3} \mathrm{~mol}^{-1} \mathrm{~K}$ and $\theta=-3.15 \mathrm{~K}$ for $\left[\{\mathrm{CuCl}(\mathrm{PzTz})\}_{2}(\mu-\mathrm{Cl})_{2}\right], C=2.78 \mathrm{~cm}^{3} \mathrm{~mol}^{-1} \mathrm{~K}$ and $\theta=-3.32 \mathrm{~K}$ for $\left[\{\mathrm{CuCl}(\mathrm{DMPzTz})\}_{2}(\mu-\mathrm{Cl})_{2}\right]$ and $C=$ $0.85 \mathrm{~cm}^{3} \mathrm{~mol}^{-1} \mathrm{~K}$ and $\theta=+0.85 \mathrm{~K}$ for $\left[\{\mathrm{CuCl}(\mathrm{DPhPzTz})\}_{2}(\mu-\mathrm{Cl})_{2}\right]$. These data indicate weak antiferromagnetic interactions between the copper(II) ions for the first two compounds and ferromagnetic coupling for the latter. Plots of the $\chi_{\mathrm{M}} T$ product versus $T$ are shown in Fig. 2 and Fig. S17 (ESI ${ }^{\mathrm{i}}$ ).
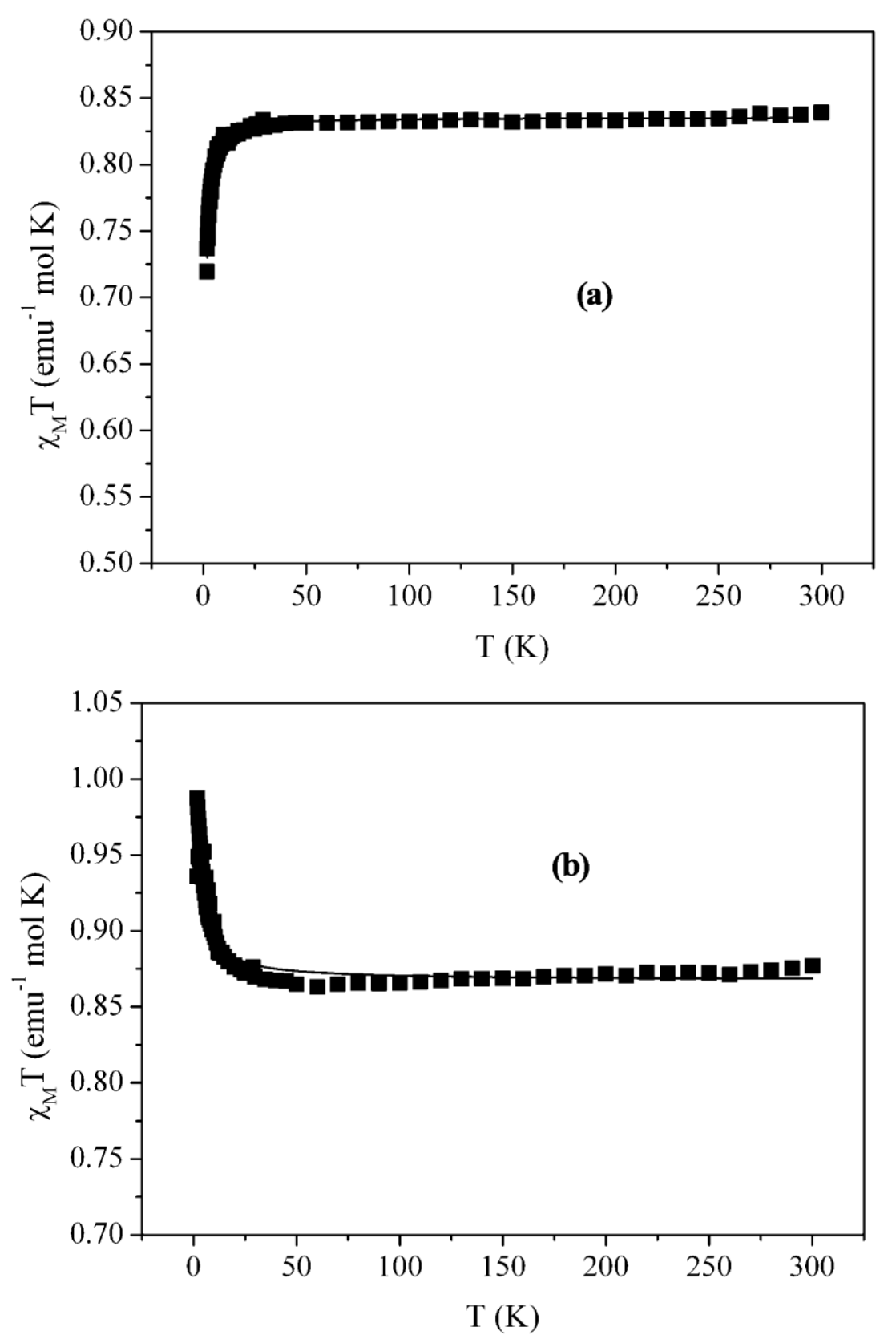

Fig. 2. Experimental $\chi_{\mathrm{M}} T$ vs. $T$ data for compounds $\left[\{\mathrm{CuCl}(\mathrm{DMPzTz})\}_{2}(\mu-\mathrm{Cl})_{2}\right]\left(\right.$ a) and $\left[\{\mathrm{CuCl}(\mathrm{DPhPzTz})\}_{2}(\mu-\mathrm{Cl})_{2}\right]$ (b). Solid lines represent the best fit of the data using the model described in the text.

The experimental data were fitted using the Bleany-Bowers equation (eqn (1)) for a dinuclear copper(II) complex. ${ }^{17}$ 


$$
\chi_{\mathrm{M}}=\frac{2 N g^{2} \mu_{\mathrm{B}}^{2}}{K_{\mathrm{B}} T\left[3+\exp \left(-2 J / K_{\mathrm{B}} T\right)\right]}
$$

The $g$ values were taken from EPR data whereas the $J$ values were determined as adjustable parameters in a least-squares fitting procedure that led to $J=-1.01 \mathrm{~cm}^{-1}$ with an agreement factor $R=1.2 \times 10^{-7}$ for $\left[\{\mathrm{CuCl}(\mathrm{PzTz})\}_{2}(\mu-\mathrm{Cl})_{2}\right]$ and $J=-0.32 \mathrm{~cm}^{-1}$ and $R=9.6 \times 10^{-11}$ for $\left[\{\mathrm{CuCl}(\mathrm{DMPzTz})\}_{2}(\mu-\mathrm{Cl})_{2}\right]$. In the case of $\left[\{\mathrm{CuCl}(\mathrm{DPhPzTz})\}_{2}(\mu-\mathrm{Cl})_{2}\right]$ the fitting improved significantly when $g$ was included in the fitting procedure, giving $g=2.15, J=0.48 \mathrm{~cm}^{-1}$ and $R=1.7 \times 10^{-8}$. The negative values of the coupling constant $J$ indicate a weak antiferromagnetic interaction in $\left[\{\mathrm{CuCl}(\mathrm{PzTz})\}_{2}(\mu-\mathrm{Cl})_{2}\right]$ and $\left[\{\mathrm{CuCl}(\mathrm{DMPzTz})\}_{2}(\mu-\mathrm{Cl})_{2}\right]$, whereas the positive value indicates a weak ferromagnetic interaction in $\left[\{\mathrm{CuCl}(\mathrm{DPhPzTz})\}_{2}(\mu-\mathrm{Cl})_{2}\right]$.

Several attempts were performed to establish magneto-structural correlations in dichlorido-bridged $\mathrm{Cu}$ (II) complexes. $^{2 \mathrm{~b}, \mathrm{c}, \mathrm{m}, \mathrm{r}, 3 \mathrm{f}, 18}$ All these correlations indicate that the exchange coupling constant $J$ depends on the value of the $\mathrm{Cu}-\mathrm{Cl}-\mathrm{Cu}$ bridging angle, $\varphi$, as well as on the bond distance of the axial $\mathrm{Cu}-\mathrm{Cl}$ bond, $R$, particularly expressed by the $\varphi / R$ ratio. In several works ${ }^{2 \mathrm{~m}, \mathrm{r}, 3 \mathrm{f}, 4 \mathrm{c}}$ the sign and magnitude of the coupling constant $J$ was related to the geometry around the paramagnetic centres (Table S3, ESI ${ }^{i}$ ). Besides, in pentacoordinated $\mathrm{Cu}(\mu-\mathrm{Cl})_{2} \mathrm{Cu}$ dimers, the magnetic coupling is influenced by the distortions of the coordination geometry. The global arrangement of the two square pyramids gives rise to three types of geometries: square pyramids sharing one base-to-apex edge with the two bases nearly perpendicular to one another (type I), square pyramids sharing one base-to-apex edge but with parallel basal planes (type II) and square pyramids sharing a basal edge with coplanar basal planes (type III). The extended Hückel calculations performed by Rodríguez et al. ${ }^{21, \mathrm{~m}}$ showed that the super exchange pathway with the metal centres takes place mainly through a $\pi^{*}$ type interaction between the $\mathrm{d}_{x}{ }^{2}-y^{2}$ orbitals of $\mathrm{Cu}$ (II) ions and the p orbitals of chloro bridging ligands for type II complexes, as is the case for $\left[\{\mathrm{CuClL}\}_{2}(\mu-\mathrm{Cl})_{2}\right](\mathrm{L}=\mathrm{PzTz}, \mathrm{DMPzTz}$ or DPhPzTz). For an ideal geometry with a square core, the overlap integral between the former orbitals would be zero, and therefore, there would not be any magnetic coupling between the copper centres. As above, these type II complexes present very small $J$ values, which are the result of structural deviations from the ideal square $\mathrm{Cu}_{2} \mathrm{Cl}_{2}$ core. Thus, the small calculated $J$ values obtained here are consistent with the calculations performed by the aforementioned authors. The magnetic orbitals obtained herein with CASSCF calculations are in line with this analysis (see below). Finally, for di- $\mu$-chloride-bridged dimers, ferromagnetic exchange interactions occur if the value of $\varphi / R$ is in the range of $32.6-34.8^{\circ} \AA^{-1}$, otherwise the interaction is antiferromagnetic. ${ }^{19}$ In the case of our complexes, the $\varphi / R$ value is $35.28^{\circ} \AA^{-1}$ for $\left[\{\mathrm{CuCl}(\mathrm{PzTz})\}_{2}(\mu-\mathrm{Cl})_{2}\right]$ consistent with antiferromagnetic interaction, $34.61^{\circ} \AA^{-1}$ for $\left[\{\mathrm{CuCl}(\mathrm{DMPzTz})\}_{2}(\mu-\right.$ $\mathrm{Cl})_{2}$ ] that shows antiferromagnetic coupling, which does not fit this trend, and $32.74^{\circ} \AA^{-1}$ for $\left[\{\mathrm{CuCl}(\mathrm{DPhPzTz})\}_{2}(\mu-\mathrm{Cl})_{2}\right]$, in line with a ferromagnetic interaction.

\section{Computational studies}

Aiming to gain information on the relative stabilities of the monomeric and dimeric forms of the complexes investigated in this work we performed DFT calculations at the TPSSh/TZVP level. Bulk solvent effects (methanol) were considered by using a polarized continuum model (PCM, see Computational details below). The optimized geometries of the mononuclear $\left[\mathrm{CuCl}_{2}(\mathrm{DMPzTz})\right]$ and dinuclear $\left[\{\mathrm{CuClL}\}_{2}(\mu-\mathrm{Cl})_{2}\right](\mathrm{L}=$ PzTz, DMPzTz or DPhPzTz) complexes show an excellent agreement with the X-ray crystal structures (Tables S4-S6, ESI ${ }^{i}$ ). The calculated $\mathrm{Cu}-\mathrm{N}$ distances differ from the experimental values by $<0.04 \AA$, while the $\mathrm{Cu}-\mathrm{Cl}$ distances present somewhat larger deviations $(0.01-0.12 \AA)$. The largest deviations are observed for the distances involving chloride ligands at the apical position of the square pyramidal coordination, which present rather long $\mathrm{Cu}-\mathrm{Cl}$ distances (experimental values in the range of $2.58-2.80 \AA$ ). 
The relative energies of the mononuclear and dinuclear forms of the complexes (including zero-point-energy corrections, $\Delta E_{\mathrm{ZPE}}$ ) calculated at the TPSSh/TZVP level according to reaction (2) are shown in Fig. 3.

$$
2\left[\mathrm{CuCl}_{2}(\mathrm{~L})\right] \leftrightarrows\left[\{\mathrm{CuClL}\}_{2}(\mu-\mathrm{Cl})_{2}\right]
$$

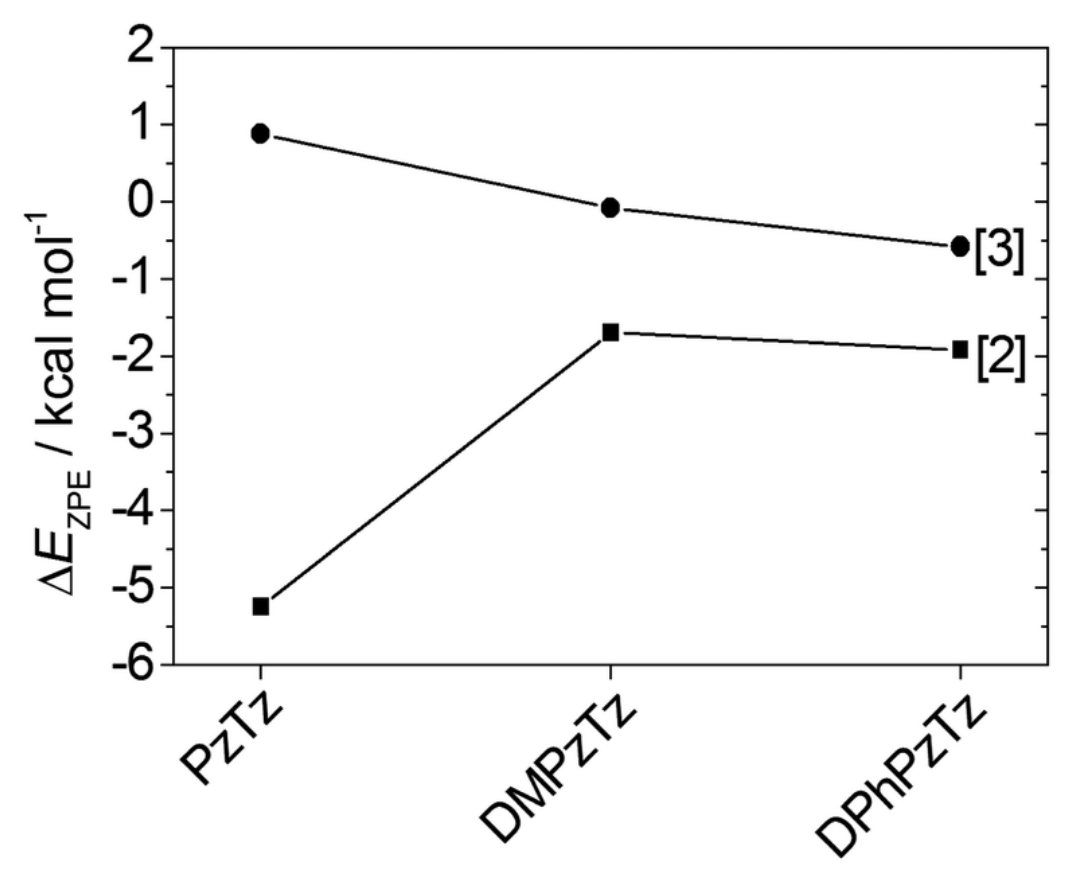

Fig. 3. Energies calculated in methanol solution for reactions (2) and (3) at the TPSSh/TZVP level.

The calculated $\Delta E_{\mathrm{ZPE}}$ values indicate that the dinuclear species are more stable than the mononuclear ones, although the inclusion of methyl or phenyl substituents provokes an important stabilization of the mononuclear forms. The smallest energy difference between the mono- and dinuclear species is predicted for the complex of DMPzTz $\left(1.69 \mathrm{kcal} \mathrm{mol}^{-1}\right)$, which was isolated in both the mono- and dinuclear forms. The relatively small energy differences between the mononuclear and dinuclear complexes of DMPzTz and DPhPzTz suggest that the equilibrium involving these species is shifted toward the dinuclear complexes, but the mononuclear species are present in solution with significant concentrations.

Concerning the relative stabilities of the cis- and trans-thiazine isomers (calculated according to eqn (3)), our calculations evidence an increasing stabilization of the trans-thiazine isomer upon inclusion of methyl and phenyl substituents at positions 2 and 5 of the pyrazole group. The two isomers are nearly isoenergetic in the case of DMPzTz, the trans-thiazine isomer being favoured by only $0.08 \mathrm{kcal} \mathrm{mol}^{-1}$. The inclusion of phenyl substituents stabilizes the trans-thiazine isomer $\left(0.58 \mathrm{kcal} \mathrm{mol}^{-1}\right.$ with respect to the cis-pyrazole isomer), while the unsubstituted ligand favours the cis-thiazine isomer by $0.88 \mathrm{kcal} \mathrm{mol}^{-1}$. These results are in line with the X-ray structures of the complexes described above. An inspection of the calculated $\mathrm{Cu}-\mathrm{N}$ bond distances (Fig. 4) provides a straightforward explanation for this trend. Indeed, the $\mathrm{Cu}-\mathrm{N}$ donor distances of the trans-thiazine isomer show a smooth decrease upon inclusion of methyl and phenyl substituents in the ligand. However, one of the $\mathrm{Cu}-\mathrm{N}$ distances of the cis-thiazine isomer experiences a dramatic increase, following the trend PzTz $<$ DMPzTz « DPhPzTz. Thus, steric effects appear to be responsible for the destabilization of the cis-thiazine isomer when increasing the bulkiness of the substituents at positions 3 and 5 of the pyrazole ring. Inspection of the structures calculated for $\left[\{\mathrm{CuCl}(\mathrm{DPhPzTz})\}_{2}(\mu-\mathrm{Cl})_{2}\right]\left(\right.$ Fig. S18, $\left.\mathrm{ESI}^{\mathrm{i}}\right)$ 
reveals short $\mathrm{H} \cdots \mathrm{H}$ distances $(<3.2 \AA)$ involving hydrogen atoms of the phenyl rings and the thiazine units of the cisisomer, which are responsible for its destabilization.

$$
\text { cis- }\left[\{\mathrm{CuClL}\}_{2}(\mu-\mathrm{Cl})_{2}\right] \leftrightarrows \text { trans- }\left[\{\mathrm{CuClL}\}_{2}(\mu-\mathrm{Cl})_{2}\right]
$$

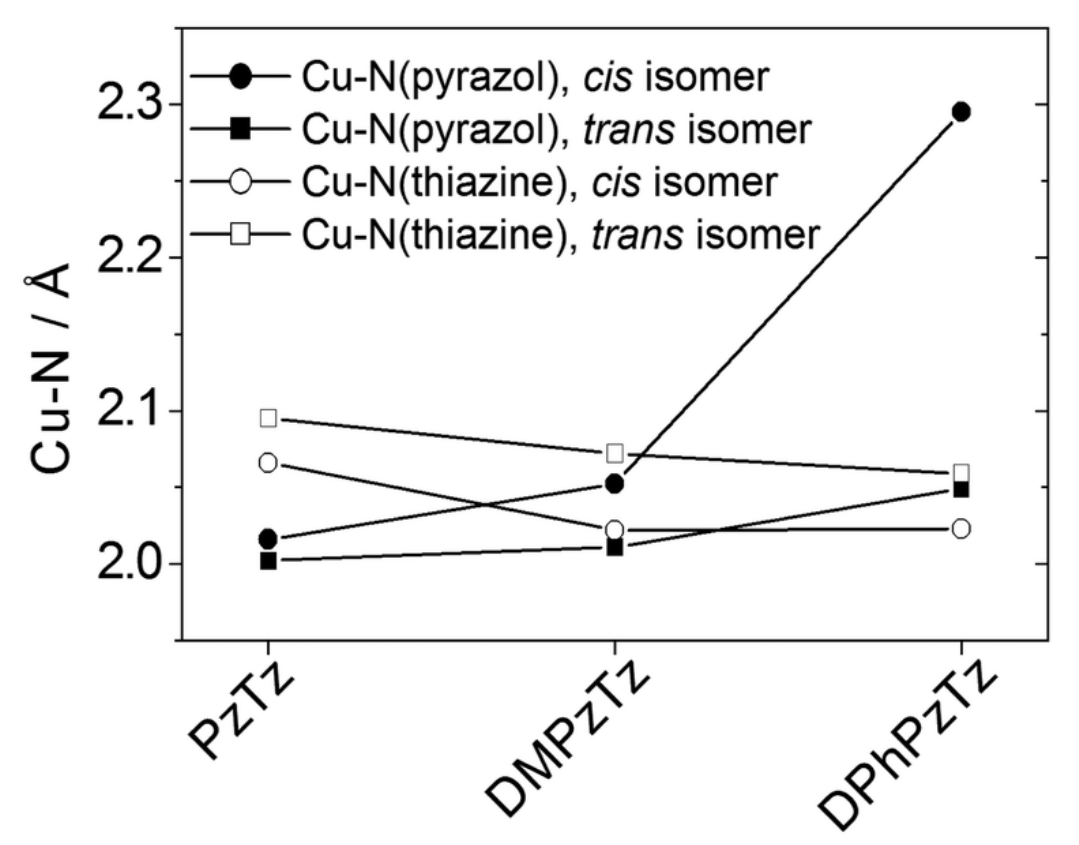

Fig. 4. $\mathrm{Cu}-\mathrm{N}$ distances calculated in methanol solution for the cis and trans isomers of $\left[\{\mathrm{CuCl}(\mathrm{DPhPzTz})\}_{2}(\mu-\mathrm{Cl})_{2}\right]$ (TPSSh/TZVP level).

DFT calculations were also used to investigate exchange coupling constants using the broken symmetry approach. ${ }^{20}$ The exchange interaction between two magnetic centers $\mathrm{A}$ and $\mathrm{B}$ with spin coupling constant $J_{\mathrm{AB}}$ and spin operators $S_{\mathrm{A}}$ and $S_{\mathrm{B}}$ can be described by the phenomenological spin Hamiltonian:

$$
H=-2 J_{\mathrm{AB}} S_{\mathrm{A}} S_{\mathrm{B}}
$$

Application of the broken symmetry approach proposed by Yamaguchi leads to the following expression: ${ }^{21,22}$

$$
J_{\mathrm{AB}}=\frac{E_{\mathrm{HS}}-E_{\mathrm{BS}}}{\left(S^{2}\right)_{\mathrm{HS}}-\left(S^{2}\right)_{\mathrm{BS}}}
$$

The exchange coupling constant, $J$, was estimated using a series of functionals (BLYP, BHLYP, TPSS, TPSSh and TPSS0) in combination with the TZVP basis set. The latter basis set was shown to provide good results in the calculation of exchange coupling constants of transition metal complexes using DFT. ${ }^{23}$ Magnetic susceptibility measurements are obtained from solid samples where packing forces may 
provoke structural changes with respect to the isolated molecules, which may affect the exchange coupling constants. ${ }^{24}$ Thus, the geometries of the cis- and trans-thiazine isomers were taken from the X-ray diffraction data of $\left[\{\mathrm{CuCl}(\mathrm{PzTz})\}_{2}(\mu-\mathrm{Cl})_{2}\right]$ and $\left[\{\mathrm{CuCl}(\mathrm{DPhTzPz})\}_{2}(\mu-\mathrm{Cl})_{2}\right]$, respectively. The positions of the hydrogen atoms were optimized at the TPSSh/TZVP level, while the positions of the remaining atoms were not optimized.

The $J$ values calculated using all functionals are positive, which would indicate a ferromagnetic interaction (Fig. 5, see also Table S7, ESI ${ }^{\mathrm{i}}$ ). For each of the tested functionals the calculated $J$ value is higher for the trans-thiazine isomer than for the cis-thiazine one. In line with previous investigations ${ }^{25}$ the magnitude of $J$ decreases when the percentage of HF exchange increases. Thus, the pure GGA functional BLYP and the meta-GGA functional TPSS give the largest calculated $J$ values, which decrease upon increasing the HF exchange to $10 \%$ (TPSSh), 25\% (TPSS0) and 50\% (BHLYP). However, the calculated $J$ values remain positive for all tested functionals, which fail to predict the antiferromagnetic coupling observed for the cis isomers.

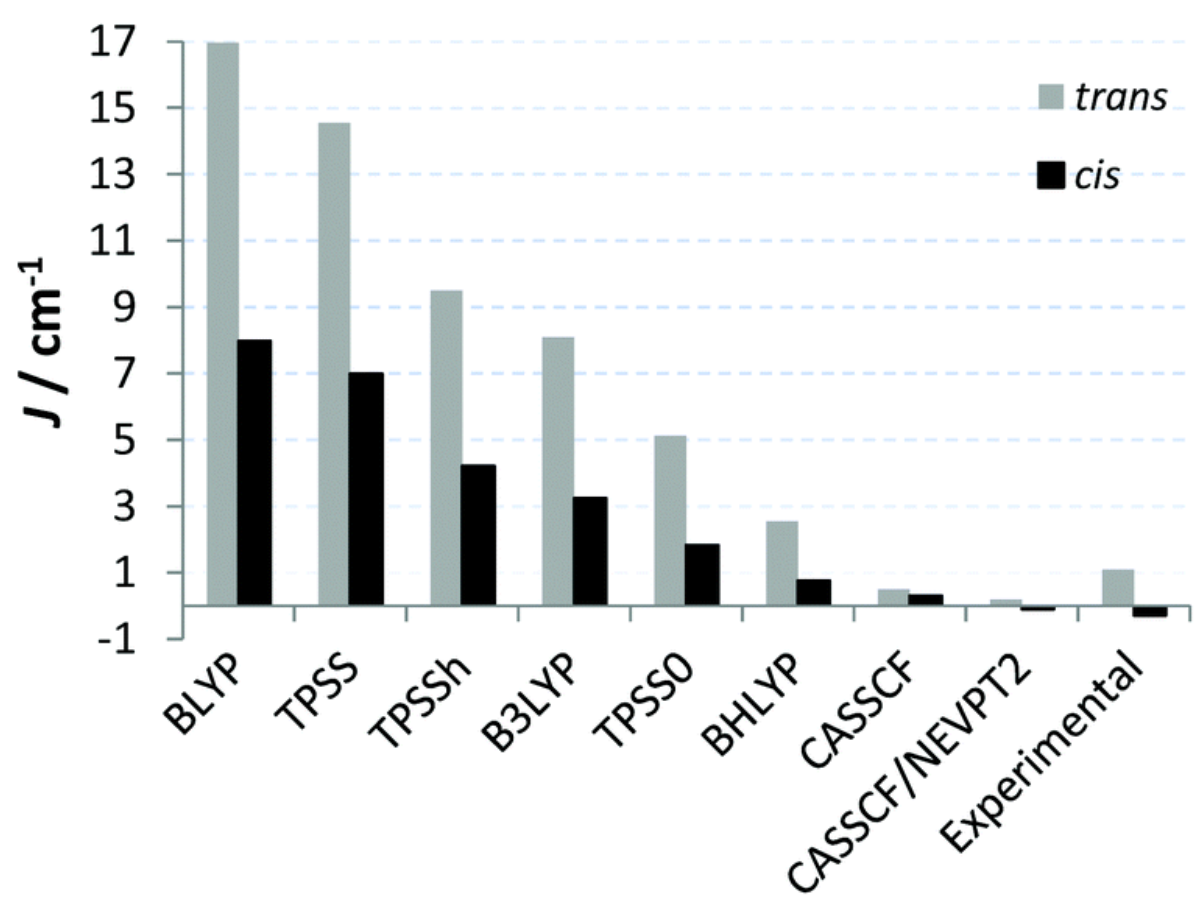

Fig. 5. Comparison of experimental and calculated exchange coupling constants of the cis and trans isomers of $[\mathrm{CuCl}(\mathrm{PzTz})]\left(\mu-\mathrm{Cl}_{2}\right)$.

In view of the failure of DFT methods to predict the sign of the magnetic coupling constants of the complexes investigated in this work, we turned our attention to multiconfigurational methods, which were shown to be an efficient tool to predict magnetic coupling in metal complexes. ${ }^{26}$ More specifically, we used calculations based on the complete active space self-consistent field (CASSCF) approach. Dynamic correlation effects were considered by using the $\mathrm{N}$-electron valence perturbation theory to second order (NEVPT2) ${ }^{27}$ which takes the CASSCF wave function as the zeroth-order wave function and estimates dynamic electron correlation effects by second order perturbation theory. Our CASSCF calculations considered the minimal active space $(\operatorname{CASSCF}(2,2))$, where the two unpaired electrons occupy the two magnetic orbitals. ${ }^{3 \mathrm{c}}$ Inspection of the magnetically active orbitals (Fig. 6) shows that they correspond to the symmetric and antisymmetric combinations of the $\mathrm{Cu} 3 \mathrm{~d}_{x}{ }^{2}-y^{2}$ orbitals with tails on the bridging and terminal chloride atoms and PzTz ligands. At the $\operatorname{CASSCF}(2,2)$ level the cis and transisomers of $\left[\{\mathrm{CuCl}(\mathrm{PzTz})\}_{2}(\mu-\right.$ 
$\mathrm{Cl}_{2}$ ] present ferromagnetic coupling, as the triplet state is the ground state. However, CASSCF/NEVPT2 calculations predict the correct sign of the exchange coupling constant, which amounts to $-0.1 \mathrm{~cm}^{-1}$ and +0.2 $\mathrm{cm}^{-1}$ for the cis and trans isomers (Fig. 5, see also Table S7, ESI ${ }^{\mathrm{i}}$ ). Thus, the inclusion of dynamic correlation appears to be critical for the prediction of the correct sign of $J$, at least for systems characterized by small $J$ values such as those investigated in this work.
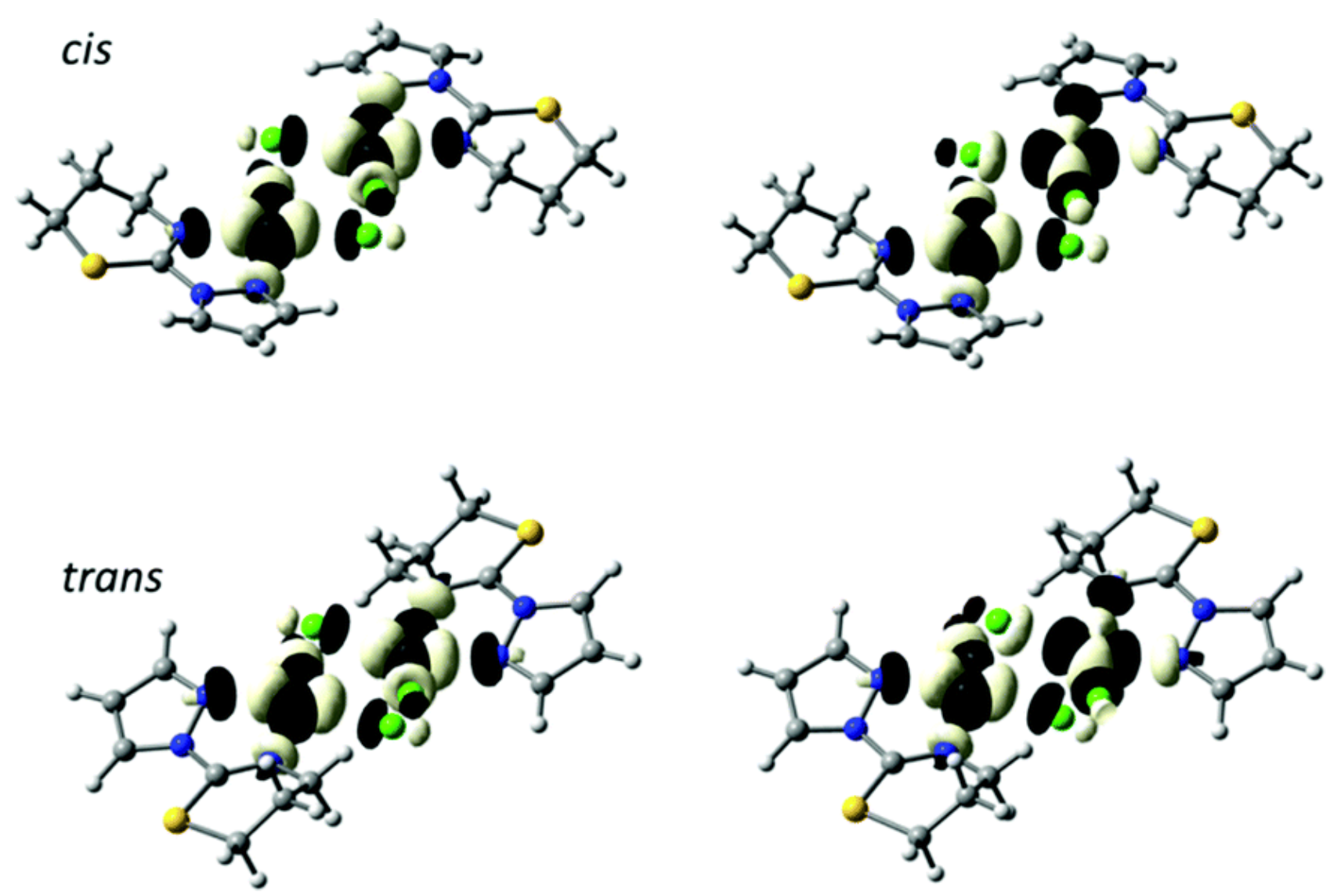

Fig. 6. Active magnetic orbitals of $[\mathrm{CuCl}(\mathrm{PzTz})]\left(\mu-\mathrm{Cl}_{2}\right)$ obtained with $\mathrm{CASSCF}(2,2)$ calculations.

\section{Conclusions}

In summary, we have reported the synthesis and characterisation of the dimeric copper(II) complexes $\left[\{\mathrm{CuCl}(\mathrm{PzTz})\}_{2}(\mu-\mathrm{Cl})_{2}\right],\left[\{\mathrm{CuCl}(\mathrm{DMPzTz})\}_{2}(\mu-\mathrm{Cl})_{2}\right]$ and $\left[\{\mathrm{CuCl}(\mathrm{DPhPzTz})\}_{2}(\mu-\mathrm{Cl})_{2}\right]$ and the monomeric complex $\left[\mathrm{CuCl}_{2}(\mathrm{DMPzTz})\right]$. The geometry around the copper(II) centers in the dimeric units can be best described as distorted square pyramidal, while the monomeric compound presents distorted squared planar coordination. The increasing steric hindrance introduced by the replacement of hydrogen atoms in positions 3 or 5 of the pyrazole ring by methyl and phenyl groups produces in $\left[\{\mathrm{CuCl}(\mathrm{DPhPzTz})\}_{2}(\mu-\mathrm{Cl})_{2}\right]$ a drastic structural change with a different orientation of the organic ligand that minimizes steric effects (a cis-thiazine isomer in $\left[\{\mathrm{CuCl}(\mathrm{PzTz})\}_{2}(\mu-\mathrm{Cl})_{2}\right]$ and $\left[\{\mathrm{CuCl}(\mathrm{DMPzTz})\}_{2}(\mu-\mathrm{Cl})_{2}\right]$ and a trans-thiazine isomer in $\left.\left[\{\mathrm{CuCl}(\mathrm{DPhPzTz})\}_{2}(\mu-\mathrm{Cl})_{2}\right]\right)$. Steric effects are also responsible for the stabilization of the mononuclear complex $\left[\mathrm{CuCl}_{2}(\mathrm{DMPzTz})\right]$, as demonstrated by DFT calculations. The different structures adopted by the $\left[\{\mathrm{CuCl}(\mathrm{PzTz})\}_{2}(\mu-\mathrm{Cl})_{2}\right]$ and $\left[\{\mathrm{CuCl}(\mathrm{DMPzTz})\}_{2}(\mu-\mathrm{Cl})_{2}\right]$ complexes with respect to the $\left[\{\mathrm{CuCl}(\mathrm{DPhPzTz})\}_{2}(\mu-\mathrm{Cl})_{2}\right]$ analogue have also an impact on the magnetic properties, which are characterized by weak antiferromagnetic interactions for the first two complexes and weak ferromagnetic 
interaction for the latter. DFT studies based on the broken symmetry approach failed to predict the correct signs of the experimental $J$ values, which were however well reproduced by multiconfigurational calculations based on the CASSCF/NEVPT2 approach.

\section{Experimental section}

\section{General remarks}

All reagents were of commercial grade used without any further purification. Ligands PzTz, DMPzTz and DPhPzTz were synthesized following previously reported methods. ${ }^{13}$ Chemical analyses of carbon, hydrogen, nitrogen and sulfur were performed by microanalytical methods using a Leco CHNS-932 microanalyser. IR spectra were recorded in the 4000-370 $\mathrm{cm}^{-1}$ range using a Thermo IR-300 spectrophotometer and $\mathrm{KBr}$ pellets, or using a PerkinElmer FT-IR 1700X spectrophotometer with Nujol mulls in the 500-150 $\mathrm{cm}^{-1}$ range. UV-Vis-NIR reflectance spectra were obtained in the $200-1400 \mathrm{~nm}$ range on a Shimadzu UV-3101 PC from pellets of the samples and using $\mathrm{BaSO}_{4}$ as a reference whereas UV-Vis spectra of complex solutions were recorded using $1 \mathrm{~cm}$ quartz cells on the same instrument.

\section{Synthesis of copper(II) complexes}

$\left[\{\mathbf{C u C l}(\mathbf{P z T z})\}_{2}(\boldsymbol{\mu}-\mathbf{C l})_{2}\right]$. A solution containing $\mathrm{CuCl}_{2} \cdot 2 \mathrm{H}_{2} \mathrm{O}(102.0 \mathrm{mg}, 0.60 \mathrm{mmol})$ in methanol (1 mL) was added to a solution of PzTz $(100.0 \mathrm{mg}, 0.60 \mathrm{mmol})$ in methanol $(10 \mathrm{~mL})$. Liquid-vapour diffusion of diethyl ether into the former gave green crystals that were filtered, washed with cold ether and air-dried. Yield 95.9 mg (53\%). $\mathrm{C}_{14} \mathrm{H}_{18} \mathrm{Cl}_{4} \mathrm{Cu}_{2} \mathrm{~N}_{6} \mathrm{~S}_{2}$ (603.34): calcd. C 27.85, H 3.01, N 13.93, S 10.63; found C 27.77, H 2.97, N 13.75, S 10.46. IR $(\mathrm{KBr})$ : thiazine ring vibrations $1603[v(\mathrm{C}=\mathrm{N})], 959,923,893,777,605,578,537,445$ $\mathrm{cm}^{-1}$; pyrazole ring vibrations: 1526, 1401, 1345, $1008 \mathrm{~cm}^{-1}$; metal-ligand vibrations: $312 v(\mathrm{Cu}-\mathrm{Cl})$, $277 v\left(\mathrm{Cu}-\mathrm{N}_{\text {pyrazole }}\right), 254 \mathrm{~cm}^{-1} v\left(\mathrm{Cu}-\mathrm{N}_{\text {thiazine }}\right)$. Diffuse reflectance spectrum $\left(\mathrm{cm}^{-1}\right): 13$ 040, 26 950, and 40980. UV-Vis $\left(\mathrm{MeOH}, 4 \times 10^{-5} \mathrm{M}\right) \lambda_{\max }\left(\mathrm{cm}^{-1}\right)(\varepsilon)\left(\mathrm{L} \mathrm{mol}^{-1} \mathrm{~cm}^{-1}\right): 13070$ (200). 40000 (32 300).

[\{CuCl(DMPzTz $\left.)\}_{2}(\mu-\mathbf{C l})_{2}\right]$ and $\left[\mathbf{C u C l}_{2}(\mathrm{DMPzTz})\right]$. A similar method to that used for $\left[\{\mathrm{CuCl}(\mathrm{PzTz})\}_{2}(\mu-\right.$ $\mathrm{Cl})_{2}$ ] using $100 \mathrm{mg}(0.51 \mathrm{mmol})$ of DMPzTz and $87.3 \mathrm{mg}(0.51 \mathrm{mmol})$ of $\mathrm{CuCl}_{2} \cdot 2 \mathrm{H}_{2} \mathrm{O}$ provided a mixture of light green crystals and a dark green solid. The light green crystals of $\left[\{\mathrm{CuCl}(\mathrm{DMPzTz})\}_{2}(\mu-\mathrm{Cl})_{2}\right]$ were separated by hand-picking from the dark green solid under a stereomicroscope. Yield $17.1 \mathrm{mg}$ (10\%). $\mathrm{C}_{18} \mathrm{H}_{26} \mathrm{Cl}_{4} \mathrm{Cu}_{2} \mathrm{~N}_{6} \mathrm{~S}_{2}$ (659.45): calcd. C 32.78, H 3.97, N 12.74, $\mathrm{S} 9.73$; found $\mathrm{C} 33.07, \mathrm{H}$ 4.12, N 12.93, $\mathrm{S}$ 9.98. IR $(\mathrm{KBr})$ : thiazine ring vibrations $1608[v(\mathrm{C}=\mathrm{N})], 906,863,740,590,551,443 \mathrm{~cm}^{-1}$; pyrazole ring vibrations: 1566, 1400, 1390, 1315, $977 \mathrm{~cm}^{-1}$; metal-ligand vibrations: 300 and $294 v(\mathrm{Cu}-\mathrm{Cl}), 285 v(\mathrm{Cu}-$ $\left.\mathrm{N}_{\text {pyrazole }}\right), 247 \mathrm{~cm}^{-1} v\left(\mathrm{Cu}-\mathrm{N}_{\text {thiazine }}\right)$. Diffuse reflectance spectrum $\left(\mathrm{cm}^{-1}\right): 13990,31060$, and 40980 . UV-Vis $\left(\mathrm{MeOH}, 4 \times 10^{-5} \mathrm{M}\right) \lambda_{\max }\left(\mathrm{cm}^{-1}\right)(\varepsilon)\left(\mathrm{L} \mathrm{mol}^{-1} \mathrm{~cm}^{-1}\right): 12850$ (200), 39680 (41 300).

The reaction carried out using acetonitrile as a solvent only provided dark green crystals by slow evaporation of the solvent. Crystals were collected by filtration and washed with cold ether to give the mononuclear complex [CuCl 2 (DMPzTz)]. Yield $136.3 \mathrm{mg}(81 \%) . \mathrm{C}_{9} \mathrm{H}_{13} \mathrm{Cl}_{2} \mathrm{CuN}_{3} \mathrm{~S}$ (329.72): calcd. C 32.78, $\mathrm{H} \mathrm{3.97,} \mathrm{N}$ 12.74, S 9.73; found $\mathrm{C} 33.06, \mathrm{H} 4.25, \mathrm{~N} 12.84, \mathrm{~S}$ 9.97. IR (KBr): thiazine ring vibrations $1592[v(\mathrm{C}=\mathrm{N})]$, 977, 865, 740, 698, 590, 551, $445 \mathrm{~cm}^{-1}$; pyrazole ring vibrations: $1560,1407,1380,1342,989 \mathrm{~cm}^{-1}$; metalligand vibrations: 336 and $308 v(\mathrm{Cu}-\mathrm{Cl}), 289 v\left(\mathrm{Cu}-\mathrm{N}_{\text {pyrazole }}\right), 271 \mathrm{~cm}^{-1} v\left(\mathrm{Cu}-\mathrm{N}_{\text {thiazine }}\right)$. Diffuse reflectance spectrum $\left(\mathrm{cm}^{-1}\right)$ : 13240,24750 , and 37 310. UV-Vis $\left(\mathrm{MeOH}, 4 \times 10^{-5} \mathrm{M}\right) \lambda_{\max }\left(\mathrm{cm}^{-1}\right)(\varepsilon)\left(\mathrm{L} \mathrm{mol}^{-1} \mathrm{~cm}^{-1}\right)$ : 12970 (140), 38840 (37 900).

$\left[\{\mathbf{C u C l}(\mathbf{D P h P z T z})\}_{2}(\boldsymbol{\mu}-\mathbf{C l})_{2}\right]$. The complex was isolated as green crystals by using a similar method to those described above using $100 \mathrm{mg}(0.31 \mathrm{mmol})$ of DPhPzTz and $53.4 \mathrm{mg}(0.31 \mathrm{mmol})$ of $\mathrm{CuCl}_{2} \cdot 2 \mathrm{H}_{2} \mathrm{O}$. Yield $109.8 \mathrm{mg}$ (77\%). $\mathrm{C}_{38} \mathrm{H}_{34} \mathrm{Cl}_{4} \mathrm{Cu}_{2} \mathrm{~N}_{6} \mathrm{~S}_{2}$ (907.71): calcd. C 50.28, H 3.77, N 9.26, S 7.06; found C 50.23, H 3.75, 
N 9.23, S 6.74. IR (KBr): thiazine ring vibrations $1614[v(\mathrm{C}=\mathrm{N})], 964,923,877,763,593,539,460 \mathrm{~cm}^{-1}$; pyrazole ring vibrations: $1554,1411,1311,1006 \mathrm{~cm}^{-1}$; metal-ligand vibrations: $310 v(\mathrm{Cu}-\mathrm{Cl}), 272 v(\mathrm{Cu}-$ $\left.\mathrm{N}_{\text {pyrazole }}\right), 259 \mathrm{~cm}^{-1} v\left(\mathrm{Cu}-\mathrm{N}_{\text {thiazine }}\right)$. Diffuse reflectance spectrum $\left(\mathrm{cm}^{-1}\right): 12$ 920, 25 380, 32 690, and 36760 . UV-Vis $\left(\mathrm{MeOH}, 4 \times 10^{-5} \mathrm{M}\right) \lambda_{\max }\left(\mathrm{cm}^{-1}\right)(\varepsilon)\left(\mathrm{L} \mathrm{mol}^{-1} \mathrm{~cm}^{-1}\right): 12870(210), 40160$ (67 730).

\section{Crystallography}

Single crystals of $\quad\left[\{\mathrm{CuCl}(\mathrm{PzTz})\}_{2}(\mu-\mathrm{Cl})_{2}\right], \quad\left[\{\mathrm{CuCl}(\mathrm{DMPzTz})\}_{2}(\mu-\mathrm{Cl})_{2}\right], \quad\left[\mathrm{CuCl}_{2}(\mathrm{DMPzTz})\right] \quad$ and $\left[\{\mathrm{CuCl}(\mathrm{DPhPzTz})\}_{2}(\mu-\mathrm{Cl})_{2}\right]$ were mounted on a Bruker X8 Kappa APEX-II diffractometer for data collection (Mo-K $\alpha$ radiation source, $\lambda=0.71073 \AA$ ). Absorption corrections were applied using the SADABS program. ${ }^{28}$ The structures were solved by direct methods and subsequent Fourier differences using the SHELXS- $97^{29}$ program and refined by full-matrix least-squares on $F^{2}$ using the SHELXL-14 ${ }^{29}$ program, included in the WINGX package, ${ }^{30}$ assuming anisotropic displacement parameters for non-hydrogen atoms. All hydrogen atoms were positioned geometrically, with $U_{\text {iso }}$ values derived from $U_{\text {eq }}$ values of the corresponding carbon atoms. The crystallographic data were summarized in Table S1 (ESI ${ }^{\mathrm{i}}$ ). The Cambridge crystallographic database ${ }^{12}$ was used to evaluate and compare the derived structural models.

\section{Magnetic measurements}

Magnetic susceptibility measurements were performed on polycrystalline samples using a magnetometer with pendulum MANICS DSM8, equipped with a helium continuous flow cryostat and an electromagnetometer DRUSCH EAF 16 UE. Data were corrected for temperature independent paramagnetism and diamagnetic contributions, which were estimated from the Pascal constants. EPR spectra were recorded at room temperature in the solid state and at $77 \mathrm{~K}$ in frozen $\mathrm{MeOH}$ employing a BRUKER ESP-300E spectrometer using the microwave X-band frequency.

\section{Computational details}

The geometries of the $\left[\mathrm{CuCl}_{2}(\mathrm{~L})\right]$ and $\left[\{\mathrm{CuClL}\}_{2}(\mu-\mathrm{Cl})_{2}\right](\mathrm{L}=\mathrm{PzTz}$, DMPzTz or DPhPzTz) systems were optimized in methanol solution at the TPSSh/TZVP level ${ }^{31}$ using the Gaussian 09 package (Revision D.01). ${ }^{32}$ Bulk solvent effects were included by using the integral equation formalism variant of the polarizable continuum model (IEFPCM) ${ }^{33}$ in which the solute cavity is built as an envelope of spheres centred on atoms or atomic groups with appropriate radii. The universal force field radii (UFF) ${ }^{34}$ scaled by a factor of 1.1 were used to define the solute cavities. No symmetry constraints have been imposed during the optimizations. The stationary points found on the potential energy surfaces as a result of geometry optimizations were tested to represent energy minima rather than saddle points via frequency analysis. The default values for the integration grid (75 radial shells and 302 angular points) and the SCF energy convergence criteria $\left(10^{-8}\right)$ were used in all calculations.

Magnetic exchange coupling constants were calculated using the ORCA program package (Version 3.0.1). ${ }^{35}$ In these calculations we tested the popular BLYP, ${ }^{36} \mathrm{~B}^{3} \mathrm{LYP}{ }^{36,37}$ and BHLYP functionals, ${ }^{36,38}$ the non-hybrid variants of TPSSh, TPSS, ${ }^{31 a}$ and TPSSO, a $25 \%$ exchange version of TPSSh (10\% exchange) that provides improved energetics, functionals. ${ }^{39}$ The geometries of the cis and trans isomers of $\left[\{\mathrm{CuCl}(\mathrm{PzTz})\}_{2}(\mu-\mathrm{Cl})_{2}\right]$ were employed for the calculation of magnetic exchange parameters. The coordinates of the non-hydrogen atoms were taken from the X-ray structures of $\left[\{\mathrm{CuCl}(\mathrm{PzTz})\}_{2}(\mu-\mathrm{Cl})_{2}\right]$ and $\left[\{\mathrm{CuCl}(\mathrm{DPhPzTz})\}_{2}(\mu-\mathrm{Cl})_{2}\right]$, while the positions of the hydrogen atoms were optimized in the gas phase at the TPSSh/TZVP level using the Gaussian code. Broken symmetry calculations were carried out using the TZVP basis set for the ligand atoms and the core properties (CP) basis set developed by Neese for $\mathrm{Cu}^{40} \mathrm{The}$ RIJCOSX approximation ${ }^{41}$ was used to speed up the calculations of the ZFS parameters using the Def2TZVPP $/ \mathrm{JK}^{42}$ auxiliary basis set as constructed automatically by ORCA. The spin-orbit contribution was considered employing the spin-orbit mean field approach (SOMF) using the one-center approximation to the 
exchange term $(\operatorname{SOMF}(1 \mathrm{X})) .{ }^{43}$ The convergence tolerances and integration accuracies of the calculations were increased from the defaults using the available TightSCF and Grid5 options (Grid7 for $\mathrm{Cu}$ ).

Nonrelativistic energy levels and wave functions were computed using the Complete Active Space SelfConsistent Field (CASSCF) method ${ }^{44}$ along with the TZVP basis set. CASSCF calculations were performed by using an active space including two electrons distributed into the two magnetically active $\mathrm{Cu} 3 \mathrm{~d}$-based molecular orbitals $(\mathrm{CASSCF}(2,2))$. The CASSCF wavefunctions were subsequently analyzed using $\mathrm{N}$ electron valence perturbation theory to second order (NEVPT2) ${ }^{27}$ The RIJCOSX approximation as described above was used to speed up both CASSCF and NEVPT2 calculations. ${ }^{41}$

\section{Acknowledgments}

P. T.-G., F. L.-G., A. B.-G. and E. V.-Z. would like to thank the Junta de Extremadura and the FEDER (Project GR15147) for financial support. C. P.-I. and D. E.-G. are also indebted to Centro de Supercomputación de Galicia (CESGA) for providing computer facilities. The authors thank Ministerio de Economía y Competitividad (CTQ2015-71211-REDT) for generous financial support.

\section{References}

1. (a) S. C. Drew, J. Inorg. Biochem., 2016, 158, 30; (b) C. Duncan and A. R. White, Metallomics, 2012, 4, 127; (c) E. I. Solomon, U. M. Sundaram and T. E. Machonkin, Chem. Rev., 1996, 96, 2563.

2. (a) X.-H. Bu, M. Du, L. Zhang, Z.-L. Shang, R.-H. Zhang and M. Shionoya, J. Chem. Soc., Dalton Trans., 2001, 729; (b)W. E. Marsh, W. E. Hatfield and D. J. Hodgson, Inorg. Chem., 1982, 21, 2679; (c) W. E. Marsh, K. C. Patel, W. E. Hatfield and D. J. Hodgson, Inorg. Chem., 1983, 22, 511; (d) H. Liu, F. Gao, D. Niu and J. Tian, Inorg. Chim. Acta, 2009, 362, 4179; (e) T. Rojo, M. I. Arriortua, J. Ruiz, J. Darriet, G. Villeneuve and D. Beltran-Porter, J. Chem. Soc., Dalton Trans., 1987, 285; (f) X.-H. Bu, M. Du, Z.-L. Shang, L. Zhang, Q.-H. Zhao, R.-H. Zhang and M. Shionoya, Eur. J. Inorg. Chem., 2001, 1551; (g) F. B. Tamboura, M. Gaye, A. S. Sall, A. H. Barry and T. Jouini,Inorg. Chem. Commun., 2002, 5, 235; (h) W. A. Alves, R. H. de Almeida Santos, A. Paduan-Filho, C. C. Becerra, A. C. Borin and A. M. Da Costa Ferreira, Inorg. Chim. Acta, 2004, 357, 2269; (i) S. Demeshko, G. Leibeling, S. Dechert and F. Meyer, Dalton Trans., 2004, 3782; (j) S.-L. Ma, X.-X. Sun, S. Gao, C.-M. Qi, H.-B. Huang and W.-X. Zhu, Eur. J. Inorg. Chem., 2007, 846; (k) E. Gungor and H. Kara, Inorg. Chim. Acta, 2012, 384, 137; (l) M. Rodríguez, A. Llobet, M. Corbella, A. E. Martell and J. Reibenspies, Inorg. Chem., 1999, 38, 2328; $(\mathrm{m})$ M. Rodríguez, A. Llobet and M. Corbella, Polyhedron, 2000, 19, 2483; (n) A. Rodríguez-Forte, P. Alemany, S. Alvarez and E. Ruiz, Inorg. Chem., 2002, 41, 3769; (o) A. M. Schuitema, A. F. Stassen, W. L. Driessen and J. Reedijk, Inorg. Chim. Acta, 2002, 337, 48; ( p) F. Tuna, L. Patron, Y. Journaux, M. Andruh, W. Plass and J.-C. Trombe, J. Chem. Soc., Dalton Trans., 1999, 539; $(q)$ R. Kapoor, A. Kataria, P. Venugopalan and P. Kapoor, Inorg. Chem., 2004, 43, 6699; (r) H. Grove, J. Sletten, M. Julve and F. Lloret, J. Chem. Soc., Dalton Trans., 2001, 2487; (s) M. Du, Y.-M. Guo, X.-H. Bu, J. Ribas and M. Monfort, New J. Chem., 2002, 26, 645; ( $t$ ) M. Du, Y.-M. Guo, X.-H. Bu, J. Ribas and M. Monfort, New J. Chem., 2002, 26, 939; (u) F. Yraola, F. Albericio, M. Corbella and M. Royo, Inorg. Chim. Acta, 2008, 361, 2455; (v) D. Žilić, B. Rakvin, D. Milić, D. Pajić, I. Đilović, M. Camettid and Z. Džolić, Dalton Trans., 2014, 43, 11877.

3. (a) Y. Sikdar, R. Modak, D. Bose, S. Banerjee, D. Bieńko, W. Zierkiewicz, A. Bieńko, K. D. Saha and S. Goswami, Dalton Trans., 2015, 44, 8876; (b) T. Todorovic, S. Grubišic, M. Pregelj, M. 
Jagodič, S. Misirlic-Denčic, M. Dulovic, I. Markovic, O. Klisuric, A. Maleševic, D. Mitic, K. Andelkovic and N. Filipovic, Eur. J. Inorg. Chem., 2015, 3921; (c) R. P. Sharma, A. Saini, P. Venugopalan, V. Ferretti, F. Spizzo, C. Angeli and C. J. Calzado, New J. Chem., 2014, 38, 574; (d) D. J. Hodgson, P. K. Hale and W. E. Hatfield, Inorg. Chem., 1971, 10, 1061; (e) A. Sasmal, S. Shit, C. Rizzoli, H. Wang, C. Desplanches and S. Mitra, Inorg. Chem., 2012, 51, 10148; (f) K. Skorda, T. C. Stamatatos, A. P. Vafiadis, A. T. Lithoxoidou, A. Terzis, S. P. Perlepes, J. Mrozinski, C. P. Raptopoulou, J. C. Plakatouras and E. G. Bakalbassis,Inorg. Chim. Acta, 2005, 358, 565; (g) R. Singh, F. Lloret and R. Mukherjee, Z. Anorg. Allg. Chem., 2014, 640, 1086.

4. (a) S. S. Roberts, D. R. Bloomquist, R. D. Willett and H. W. Dodgen, J. Am. Chem. Soc., 1981, 103, 2603; (b) S. K. Hoffmann, D. J. Hodgson and W. E. Hatfield, Inorg. Chem., 1985, 24, 1194; (c) S. Thakurta, P. Roy, G. Rosair, C. J. Gómez-García, E. Garribba and S. Mitra, Polyhedron, 2009, 28, 695; (d) P. Jeffrey Hay, J. C. Thibeault and R. Hoffmann, J. Am. Chem. Soc., 1975, 97, 4884.

5. B. J. Hathaway, in Late Transitions elements, ed. G. Wilkinson, Pergamon Press, Oxford, 1987, vol. 5, p. 594.

6. (a) P. J. Benites, R. C. Holmberg, D. S. Rawat, B. J. Kraft, L. J. Klein, D. G. Peters, H. H. Thorp and J. M. Zaleski, J. Am. Chem. Soc., 2003, 125, 6434; (b) E. Viñuelas-Zahínos, F. Luna-Giles, P. Torres-García and A. Bernalte-García,Polyhedron, 2009, 28, 4056.

7. K. Burger, Coordination Chemistry: Experimental Methods, Butterworths, London, 1973, p. 94.

8. A. W. Addison, T. N. Rao, J. Reedijk, J. Van Rijn and G. C. Verschorr, J. Chem. Soc., Dalton Trans., 1984, 1349.

9. (a) E. L. Muetterties and L. J. Guggenberger, J. Am. Chem. Soc., 1974, 96, 1748; (b) M. I. Arriortua, J. Via, J. I. R. Larramendi, B. Díaz, L. Lezama and T. Rojo, Polyhedron, 1991, 10, 495.

10. (a) A. Carné-Sánchez, C. S. Bonnet, I. Imaz, J. Lorenzo, E. Tóth and D. Maspoch, J. Am. Chem. Soc., 2013, 135, 17711; (b) Y. Habata, M. Ikeda, A. K. Sah, K. Noto and S. Kuwahara, Inorg. Chem., 2013, 52, 11697; (c) C. V. Esteves, J. Madureira, L. M. P. Lima, P. Mateus, I. Bento and R. Delgado, Inorg. Chem., 2014, 53, 4371.

11. L. Yang, D. R. Powell and R. P. Houser, Dalton Trans., 2007, 955.

12. I. J. Bruno, J. C. Cole, P. R. Edgington, M. Kessler, C. F. Macrae, P. McCabe, J. Pearson and R. Taylor, Acta Crystallogr., Sect. B: Struct. Sci., 2002, 58, 389.

13. P. Torres-García, E. Viñuelas-Zahínos, F. Luna-Giles, J. Espino and F. J. Barros-García, Polyhedron, 2011, 30, 2627.

14. (a) B. J. Hathaway, J. Chem. Soc., Dalton Trans., 1972, 1196; (b) S. Tyagi and B. J. Hathaway, J. Chem. Soc., Dalton Trans., 1981, 2029.

15. M. Joseph, V. Suni, M. R. Prathapachandra Kurup, M. Nethaji, A. Kishore and S. G. Bhat, Polyhedron, 2004, 23, 3069.

16. G. Albertin, E. Bordignon and A. A. Orio, Inorg. Chem., 1975, 14, 1411.

17. B. Bleaney and K. D. Bowers, Proc. R. Soc. London, Ser. A, 1952, 214, 451.

18. S. G. N. Roundhill, D. M. Roundhill, D. R. Bloomquist, C. Landee, R. D. Willett, D. M. Dooley and H. B. Gray, Inorg. Chem., 1979, 18, 831. 
19. W. E. Hatfield, in Magneto-Structural Correlations in Exchange Coupled Systems, ed. R. D. Willett, D. Gatteschi and O. Khan, NATO ASI Series C, Reidel, Dordrecht, The Netherlands, 1985, vol. 140, p. 555.

20. (a) L. Noodleman and J. G. Norman, Jr., J. Chem. Phys., 1979, 70, 4903; (b) L. Noodleman and E. R. Davidson, Chem. Phys., 1986, 109, 131.

21. K. Yamaguchi, Y. Takahara and T. Fueno, in Applied Quantum Chemistry, ed. V. H. Smith, Reidel, Dordrech, 1986, p. 155.

22. T. Soda, Y. Kitagawa, T. Onishi, Y. Tagano, Y. Shigeta, H. Nagao, Y. Yoshioka and K. Yamaguchi, Chem. Phys. Lett., 2000, 319, 223.

23. P. Comba, S. Hausberg and B. Martin, J. Phys. Chem. A, 2009, 113, 6751.

24. (a) E. Ruiz, P. Alemany, S. Alvarez and J. Cano, J. Am. Chem. Soc., 1997, 119, 1297; (b) E. Ruiz, J. Cano, S. Alvarez and P. Alemany, J. Comput. Chem., 1999, 20, 1391.

25. G. Rajamaran, F. Totti, A. Bencini, A. Caneschi, R. Sessoli and D. Gatteschi, Dalton Trans., 2009, 3153.

26. C. De Graaf, C. Sousa, I. De P. R. Moreira and F. Illas, J. Phys. Chem. A, 2001, 105, 11371.

27. (a) C. Angeli, R. Cimiraglia and J.-P. Malrieu, Chem. Phys. Lett., 2001, 350, 297; (b) C. Angeli, R. Cimiraglia and J.-P. Malrieu, J. Chem. Phys., 2002, 117, 9138; (c) C. Angeli, R. Cimiraglia, S. Evangelisti, T. Leininger and J.-P. Malrieu, J. Chem. Phys., 2001, 114, 10252; (d) C. Angeli and R. Cimiraglia, Theor. Chem. Acc., 2002, 107, 313.

28. Bruker AXS Inc SADABS, version 2.03 Bruker AXS Inc., Madison, WI, 2001.

29. G. M. Sheldrick, SHELXS-97 and SHELXL-14, Programs for X-ray Crystal Structure Solution and Refinement, University of Götingen, Germany, 2014.

30. L. J. Farrugia, J. Appl. Crystallogr., 1999, 32, 837.

31. (a) J. M. Tao, J. P. Perdew, V. N. Staroverov and G. E. Scuseria, Phys. Rev. Lett., 2003, 91, 146401; (b) A. Schaefer, C. Huber and R. Ahlrichs, J. Chem. Phys., 1994, 100, 5829.

32. M. J. Frisch, G. W. Trucks, H. B. Schlegel, G. E. Scuseria, M. A. Robb, J. R. Cheeseman, G. Scalmani, V. Barone, B. Mennucci, G. A. Petersson, H. Nakatsuji, M. Caricato, X. Li, H. P. Hratchian, A. F. Izmaylov, J. Bloino, G. Zheng, J. L. Sonnenberg, M. Hada, M. Ehara, K. Toyota, R. Fukuda, J. Hasegawa, M. Ishida, T. Nakajima, Y. Honda, O. Kitao, H. Nakai, T. Vreven, J. A. Montgomery, Jr., J. E. Peralta, F. Ogliaro, M. Bearpark, J. J. Heyd, E. Brothers, K. N. Kudin, V. N. Staroverov, R. Kobayashi, J. Normand, K. Raghavachari, A. Rendell, J. C. Burant, S. S. Iyengar, J. Tomasi, M. Cossi, N. Rega, J. M. Millam, M. Klene, J. E. Knox, J. B. Cross, V. Bakken, C. Adamo, J. Jaramillo, R. Gomperts, R. E. Stratmann, O. Yazyev, A. J. Austin, R. Cammi, C. Pomelli, J. W. Ochterski, R. L. Martin, K. Morokuma, V. G. Zakrzewski, G. A. Voth, P. Salvador, J. J. Dannenberg, S. Dapprich, A. D. Daniels, Ö. Farkas, J. B. Foresman, J. V. Ortiz, J. Cioslowski and D. J. Fox, Gaussian 09, Revision D.1, Gaussian, Inc., Wallingford, CT, 2009.

33. J. Tomasi, B. Mennucci and R. Cammi, Chem. Rev., 2005, 105, 2999.

34. A. K. Rappe, C. J. Casewit, K. S. Colwell, W. A. Goddard III and W. M. Skiff, J. Am. Chem. Soc., 1992, 114, 10024. 
35. F. Neese and The ORCA program system, Wiley Interdiscip. Rev.: Comput. Mol. Sci., 2012, $2,73$.

36. (a) A. D. Becke, Phys. Rev. A: At., Mol., Opt. Phys., 1988, 38, 3098; (b) C. Lee, W. Yang and R. G. Parr, Phys. Rev. B: Condens. Matter Mater. Phys., 1988, 37, 785.

37. A. D. Becke, J. Chem. Phys., 1993, 98, 5648.

38. A. D. Becke, J. Chem. Phys., 1993, 98, 1372.

39. S. Grimme, J. Phys. Chem. A, 2005, 109, 3067.

40. The CP basis is based on the TurboMole DZ basis developed by Ahlrichs and co-workers and obtained from the basis set library under http://ftp.chemie.unikarlsruhe.de/pub/basen.

41. (a) F. Neese, F. Wennmohs, A. Hansen and U. Becker, Chem. Phys., 2009, 356, 98; (b) R. Izsak and F. Neese,J. Chem. Phys., 2011, 135, 144105; (c) T. Petrenko, S. Kossmann and F. Neese, J. Chem. Phys., 2011, 134, 054116; (d) S. Kossmann and F. Neese, Chem. Phys. Lett., 2009, 481, 240.

42. F. Weigend and R. Ahlrichs, Phys. Chem. Chem. Phys., 2005, 7, 3297.

43. F. Neese, J. Chem. Phys., 2005, 122, 034107.

44. P.-A. Malqvist and B. O. Roos, Chem. Phys. Lett., 1989, 155, 189.

\footnotetext{
${ }^{\mathrm{i}}$ Electronic supplementary information (ESI) available: Crystal data and structural refinement details (Table S1), comparison of bond lengths in complexes with the mean value calculated for similar compounds (Table S2), IR spectra (Fig. S1-S8), EPR spectra (Fig. S9-S16), variable temperature magnetic susceptibility (Fig. S17), structural and magnetic parameters for dimers (Table S3), comparison of experimental and calculated bond distances (Tables S4-S6), comparison of experimental and calculated exchange coupling constants (Table S7), and calculated optimized Cartesian coordinates ( $\AA$ ) (Tables S8-S16). CCDC 1532496-1532499. For ESI and crystallographic data in CIF or other electronic format see DOI: $10.1039 / \mathrm{c} 7 \mathrm{nj} 01581 \mathrm{j}$.
} 